\title{
TIPS AND TRICKS FOR CHARACTERIZING SHAPE MEMORY ALLOY WIRE: PART 4 - THERMO-MECHANICAL COUPLING
}

\author{
by C.B. Churchill, J.A. Shaw and M.A. Iadicola
}

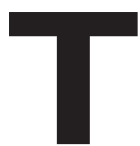

his is the fourth paper in our series, identifying unusual phenomena and providing recommendations for the thermo-mechanical characterization of shape memory alloy (SMA) wire. Part $1^{1}$ provided basic background of the martensitic transformations between austenite $(A)$ and martensite $(M)$ which are responsible for the shape memory (SM) effect and superelasticity (SE). Two typical NiTi SMA alloys (SM wire with austenite start temperature $A_{\mathrm{S}}>20^{\circ} \mathrm{C}$ and $\mathrm{SE}$ wire with austenite finish temperature $A_{\mathrm{f}}<20^{\circ} \mathrm{C}$ ) were characterized by differential scanning calorimetry (DSC) to measure transformation temperatures, specific heats, and latent heats of transformation. SM and SE were demonstrated for each alloy in their respective temperature regimes. Part $2^{2}$ reviewed various methods to obtain fundamental sets of isothermal mechanical responses for the two SMA wire alloys. Part $3^{3}$ highlighted the unusual phenomena of strain localization and phase front propagation that can occur during stress-induced transformations.

This paper (Part 4) further investigates thermo-mechanical coupling effects, focusing on the superelastic responses of SMA wire. Experiments on the same two NiTi alloys will show how this coupling, as well as the strain localization phenomenon explored in Part 3, combine to form unusual sensitivities to loading rate, thermal conditions, and specimen geometry. It is well known that the response of SMAs is loading-rate dependent. It is somewhat less appreciated that the response is also dependent on the nature of the ambient medium, even at the same loading rate. Although conventional materials exhibit viscoelastic (or viscoplastic) rate dependence in certain loading rate regimes, we will show that SMAs are different. Rate dependence in SMAs should be understood in the broader subject of thermomechanical coupling, which originates from latent heats of transformation and the dependence of transformation stress on temperature.

Disclaimer: The full description of the procedures used in this paper requires the identification of a certain commercial equipment. The inclusion of such information should in no way be construed as indicating that such a product is endorsed or recommended by NIST or that it is necessarily the best for the purposes described.

Editor's Note: This ET feature series is intended as an introduction to this exciting area of experimental mechanics. It aims to increase awareness of active materials and to promote their consistent characterization by disseminating best practices from leading researchers in the field. Each article in the series will address the characterization of one commercially significant active material. Series editors: Nilesh D. Mankame and Paul W. Alexander.

C.B. Churchill (churchc@umich.edu) and J.A. Shaw (jashaw@umich.edu), Department of Aerospace Engineering, The University of Michigan, Ann Arbor, MI. M.A. Iadicola, National Institute of Standards and Technology, Gaithersburg, $M D$.
First, five experiments on $S M$ wire are presented to demonstrate typical ambient media (water vs. air) and loading rate sensitivities in the superelastic response. Next, five experiments on $S E$ wire in room temperature air across five decades in loading rate show how latent heat interactions between the SMA material and its surroundings lead to loading-rate effects and complex phase front kinetics. This loading-rate sensitivity is exacerbated by the localized nature of transformation and the nonuniform, time-dependent temperature fields, causing hypersensitive dependence at loading rates one might normally consider quasi-static for conventional materials. A summary table of properties and nomenclature of both NiTi alloys is provided in Table 1 for reference.

\section{SHAPE MEMORY WIRE EXPERIMENTS IN WATER AND AIR}

Loading rate and ambient media sensitivities of the mechanical response will first be illustrated with experiments at a superelastic temperature on the SM wire (supplied by SAES Memory Corp., Bethel, CT) which has a diameter of $1.067 \mathrm{~mm}(0.042 \mathrm{in}$.) and an austenite finish temperature of $A_{\mathrm{f}}=56^{\circ} \mathrm{C}$. Each experiment below was performed on a fresh (as-received) specimen having a free length of about $L=63.5 \mathrm{~mm}$ (2.5 in.) in grip-displacement control (tensile elongation, $\delta$ ) while monitoring the axial tensile force $(P)$, extensometer strain $\left(\varepsilon_{\mathrm{e}}\right)$, and specimen temperature $(T)$. The axial load was measured by a load cell in series with the specimen. The extensometer used was a custom-built, miniature, waterproof extensometer with an initial local gage length of about $L_{\mathrm{e} 0}=2.54 \mathrm{~mm}\left(0.10 \mathrm{in}\right.$.) between knife edges (see ref. ${ }^{4}$ for details) that was attached to the specimen either at $L / 4$ or $L / 2$ along its free length. One, or more, small $(0.076 \mathrm{~mm}$ diameter wire) K-type, exposed-junction thermocouples were attached to the wire specimen by small spring-loaded clips (model 4233 micro grabber, Pomona Electronics) and thermally conductive, electrically insulating paste (OmegaTherm 201, filled silicone grease) to ensure good thermal contact between the wire specimen and the bead of the thermocouple junction. Experiments were performed in a testing machine at a constant elongation rate $(\dot{\delta})$ with specimen and grips immersed in a temperature-controlled liquid bath (water or silicone oil, depending on the temperature, using a setup like Fig. 1 of Part $2^{2}$ ) or a temperature-controlled air chamber.

Figure 1 shows the superelastic responses of four experiments on SM wire at a nominal ambient temperature of $T_{\mathrm{a}}=70^{\circ} \mathrm{C}$, so each specimen started in the $A$ phase. Figure 1a shows a comparison of mechanical responses in water (thin line) versus air (bold line) at the same slow elongation rate of $\dot{\delta} / L= \pm 4 \times 10^{-4} \mathrm{~s}^{-1}$ for loading then 


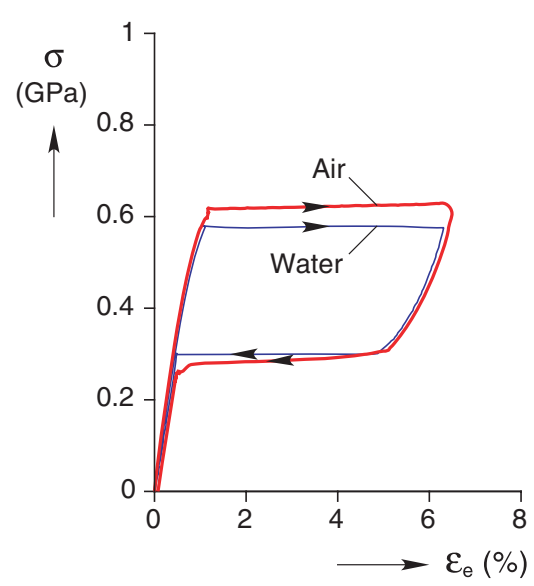

(a)

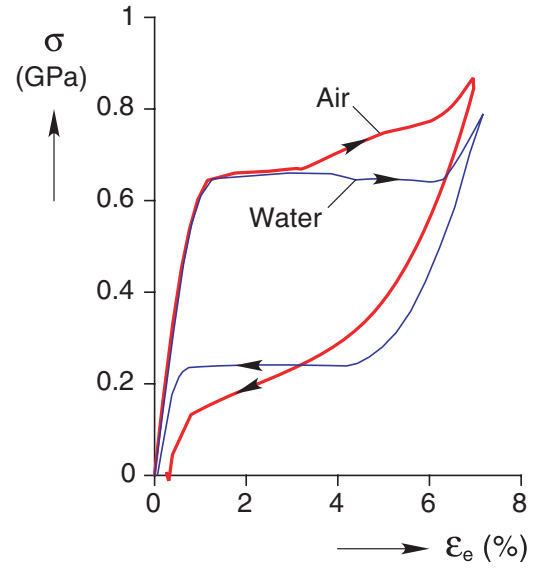

(b)

Fig. I: Four uniaxial tension responses, engineering stress $(\sigma)$ versus extensometer strain $\left(\varepsilon_{\mathrm{e}}\right)$, of SM wire at two rates in $70^{\circ} \mathrm{C}$ water and air: (a) $\dot{\delta} / L= \pm 4 \times 10^{-4} \mathrm{~s}^{-1}$ and (b) $\dot{\delta} / L= \pm 4 \times 10^{-2} \mathrm{~s}^{-1}$. Data were taken from ref. 5

unloading. Figure $1 \mathrm{~b}$ shows a similar comparison of two mechanical responses, water versus air, at a rate 100 times as fast, $\dot{\delta} / L= \pm 4 \times 10^{-2} \mathrm{~s}^{-1}$. The axial stress is reported as the engineering stress $\sigma \equiv P / A_{0}$, where $A_{0}$ is the initial wire cross-sectional area, and the strain measure is the local axial strain measured by the miniature extensometer, $\varepsilon_{\mathrm{e}}$. The grip (global) strain is controlled and measured as $\delta / L$, but it is not shown since it was affected by some grip slippage early in the $A \rightarrow M^{+}$transformation for the reasons previously discussed in Part $3^{3}$.

At the slower rate (Fig. 1a), the maximum local strains measured were $\varepsilon_{\mathrm{e}}=6.3$ and $6.5 \%$ for the water and air experiments, respectively, just before exhaustion of the loading stress plateau, at which point the cross-head motion was reversed to unload the specimen. Both experiments show the characteristic superelastic response, but differences are apparent in the responses for the two ambient media, despite being performed at the same temperature and loading rate. The $A \rightarrow M^{+}$stress plateau (loading) for the air experiment is elevated above that of the water experiment, and the $A \leftarrow M^{+}$stress plateau (unloading) in air is suppressed somewhat compared with the case in air. The strain recovery is essentially perfect in the water experiment, but a small residual strain $(0.07 \%)$ was measured in the air experiment. This was probably due to the somewhat higher maximum stress (629 $\mathrm{MPa}$ in air versus $581 \mathrm{MPa}$ in water) during the experiment, indicating that transformation-induced plasticity begins to affect the recoverable strain starting at stresses somewhere near $600 \mathrm{MPa}$ for this alloy.

The differences in air versus water as shown in Fig. 1b are more significant at the faster elongation rate, $\dot{\delta} / L=$ $\pm 4 \times 10^{-2} \mathrm{~s}^{-1}$. In these two experiments, loading was taken a bit further until the extensometer strains reached 7.2 and $7.0 \%$ for water and air, respectively, before unloading. The water experiment still shows distinct stress plateaus, albeit higher for $A \rightarrow M^{+}$and lower for $A \leftarrow M^{+}$than for the slower rate experiments. The air experiment, however, shows a momentary stress plateau for $A \rightarrow M^{+}$transformation, but then diverges upward, and the response has no plateau during $A \leftarrow M^{+}$unloading, just a nonlinear shape. The maximum stress was $789 \mathrm{MPa}$ in the water experiment and $868 \mathrm{MPa}$ in the air experiment (despite the fact that the corresponding maximum strain was slightly less). As a result, the residual strain was $0.13 \%$ in the water experiment and $0.29 \%$ in the air experiment. Again, it is interesting (perhaps surprising) that superelastic responses are so sensitive to the ambient medium, despite the otherwise similar experimental conditions. Furthermore, the first three experiments (not the faster one in air) exhibit stress plateaus, and under load control conditions (rather than elongation control shown here) would be unstable, undergoing sudden jumps in strain during transformation. The faster rate experiment in air, however, has a positive tangent modulus everywhere (even during the early $A \rightarrow M^{+}$), suggesting a stable behavior in load control.

\section{Sensitivities to Temperature, Ambient Media, and Loading Rates}

The reason for these response differences is related to the material's inherent thermo-mechanical coupling. Part $1^{1}$ showed how latent heat is released or absorbed during $A \leftrightarrow$ $M$ transformations. Part $2^{2}$ showed the strong temperature dependence on the characteristic transformation stresses, and this is worth reviewing in some more detail here. Figure $2 \mathrm{a}$ presents the responses (slow loading rate, $\dot{\delta} / L= \pm 4 \times 10^{-4} \mathrm{~s}^{-1}$, in water) of SM wire (from Part 2), focusing on just the superelastic range of temperatures. The characteristic plateau stresses $\left(\sigma_{\mathrm{P}}\right)$ for the forward $(A \rightarrow$ $\left.M^{+}\right)$and reverse $\left(A \leftarrow M^{+}\right)$stress-induced transformations are plotted against temperature in Fig. 2b, and the lengths of these plateaus (plateau strains, $\Delta \varepsilon_{\mathrm{P}}$ ) are plotted in Fig. $2 c$ 


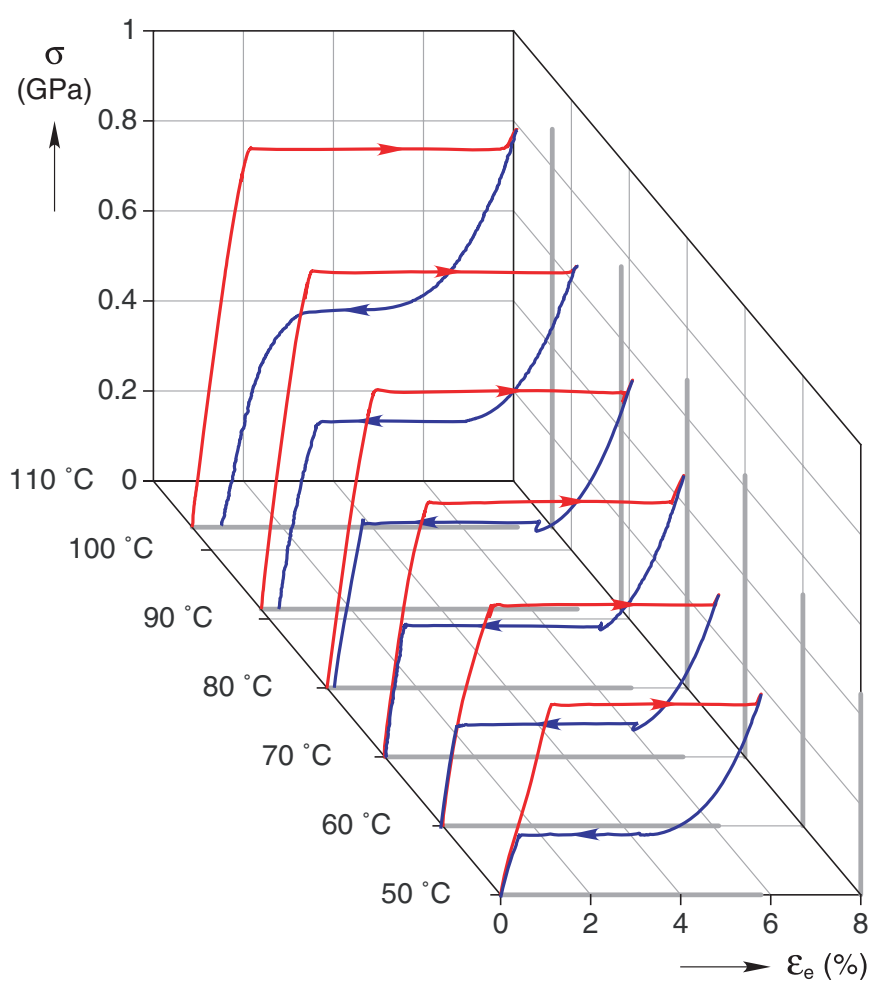

(a)

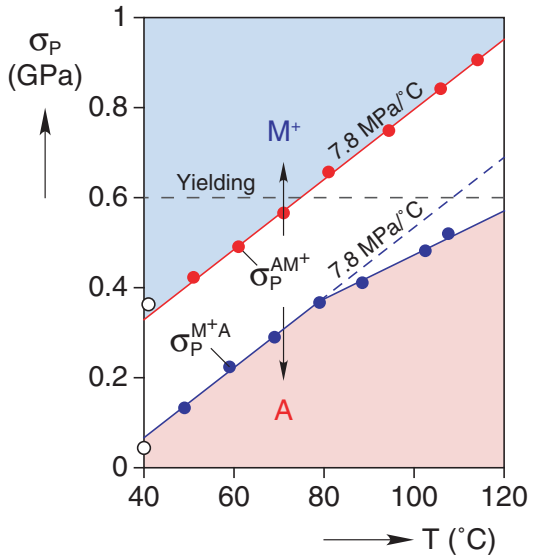

(b)

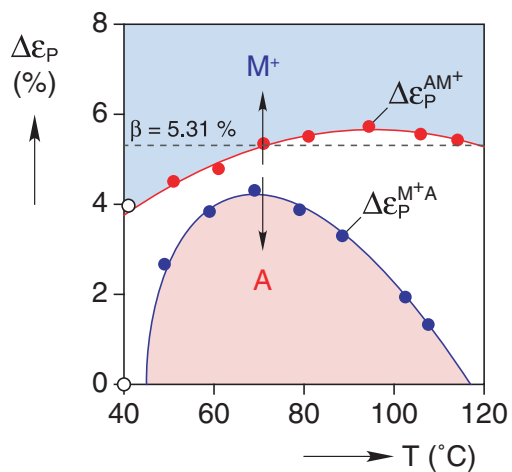

(c)

Fig. 2: (a) Isothermal mechanical responses of SM wire (data were taken from ref. ${ }^{5}$ ), (b) plateau stresses, and (c) plateau strains

(uncertainties are less than the size of the data symbols). The general trend in Fig. 2b is a dramatic rise (linear, up to a point) in both plateau stresses with increasing temperature; whereas, the plateau strains in Fig. 2c for $A \rightarrow M^{+}$and $A \leftarrow M^{+}$increase then decrease in a nonlinear way with temperature. The forward plateau strain $\left(\Delta \varepsilon_{\mathrm{P}}^{A M^{+}}\right)$rises gently, reaching a maximum of $5.73 \%$ near $94^{\circ} \mathrm{C}$ then decreases gently for higher temperatures. The reverse plateau strain grows steeply from zero at some temperature between 40 and $50^{\circ} \mathrm{C}$ to a maximum of $4.31 \%$ near $69^{\circ} \mathrm{C}$, then drops off at higher temperatures.

The temperatures in Fig. $2 \mathrm{~b}$ and $2 \mathrm{c}$ have been shifted slightly from the ambient temperature based on the maximum temperature during $A \rightarrow M^{+}$and minimum temperature during $A \leftarrow M^{+}$recorded by the thermocouple (discussed further below). These figures also include data points from two experiments outside the temperature range shown in Fig. 2a (one colder and one hotter). The slanted lines in Fig. $2 b$ are linear fits of the selected transformation stresses. The $\sigma_{\mathrm{P}}^{A M^{+}}$data are fit very well by a $7.8 \mathrm{MPa} /{ }^{\circ} \mathrm{C}$ slope at temperatures above $50^{\circ} \mathrm{C}$. We should mention that this is a more refined fit than the $9.3 \mathrm{MPa} /{ }^{\circ} \mathrm{C}$ slope indicated in Part 2, which used the ambient temperature and did not account for specimen temperature changes during the experiment. Below $50^{\circ} \mathrm{C}$ the upper plateau stresses rise above the fit somewhat, because the initial phase is a near equal mixture of $A$ and $R$ at $40^{\circ} \mathrm{C}$ according to the DSC thermogram of Fig. 3a of Part 1 and involves more than just $A \rightarrow M^{+}$transformation (hence the open circles shown). The lower plateau stresses $A \leftarrow M^{+}$fit the $7.8 \mathrm{MPa} /{ }^{\circ} \mathrm{C}$ slope well between 50 and $80^{\circ} \mathrm{C}$ but then depart below it at larger temperatures.

The temperature where the fit in Fig. $2 \mathrm{~b}$ no longer agrees with the $\sigma_{\mathrm{P}}^{M^{+} A}$ data is somewhere between 70 and $80^{\circ} \mathrm{C}$. This corresponds to the intersection of the upper fit of the $\sigma_{\mathrm{P}}^{A M^{+}}$data and the $600 \mathrm{MPa}$ dashed line, where yielding (significant dislocation motion and generation) is expected to begin. Note this is also the temperature range where the $\Delta \varepsilon_{\mathrm{P}}^{M^{+} A}$ data in Fig. $2 \mathrm{c}$ starts to decrease significantly with increasing temperature and where progressively larger residual strains exist at the end of the load-unload experiments in Fig. 2a. This is probably due to plasticity 
that occurred simultaneously during loading as the $A \rightarrow$ $M^{+}$transformation stresses become quite large at high temperatures. Residual stresses are created during loading that "lock-in" micropockets of martensite and thus require a suppressed macroscopic stress before the reversion to austenite $\left(A \leftarrow M^{+}\right)$can occur $\left(\sigma_{\mathrm{P}}^{M^{+} A}\right.$ in Fig. $\left.2 \mathrm{~b}\right)$. The highest temperature at which perfect SE (closed hysteresis loop) occurs is about $70^{\circ} \mathrm{C}$ for this alloy (Fig. 2a).

It seems that in the absence of competing effects, such as plasticity or other phase transformations $\left(R^{+} \rightarrow M^{+}\right)$, $7.8 \mathrm{MPa} /{ }^{\circ} \mathrm{C}$ is the slope of a canonical stress-temperature line separating stable regimes of austenite $(A)$ and stressinduced martensite $\left(M^{+}\right)$. The positive slope of this line creates a progressively larger linear elastic range for $A$ as the temperature is raised, creating the appearance that $A$ actually grows stronger with temperature. Why should this be so? The short answer is that under stress-free conditions $A$ is stable (lower free energy) at high temperatures and $M$ is stable (lower free energy) at low temperatures, thus it seems reasonable that as the temperature is increased above $M$ 's naturally stable temperature range it requires progressively larger stresses to stabilize it (lower its free energy sufficiently) relative to $A$. One can estimate this line using equilibrium thermodynamics by the classical Clausius-Clapeyron relation specialized to uniaxial stress,

$$
\left(\frac{\mathrm{d} \sigma_{\mathrm{P}}}{\mathrm{d} T}\right)_{\text {eqm }}=-\rho\left(\frac{\Delta s}{\Delta \varepsilon}\right)^{A \rightarrow M^{+}},
$$

where $\rho=6.5 \times 10^{6} \mathrm{~g} / \mathrm{m}^{3}$ is the SMA mass density, $\Delta s \equiv$ $s_{M}-s_{A}$ (a negative quantity) is the specific entropy jump and $\Delta \varepsilon$ is the transformation strain jump from $A \rightarrow M^{+}$. The entropy jump can be estimated from the reverse transformation in the DSC thermogram from Part 1 as $\Delta s \approx$ $-\Lambda^{M \rightarrow A} / T_{\mathrm{R}}$, where $\Lambda^{M \rightarrow A}=19.7 \mathrm{~J} / \mathrm{g}$ and $T_{\mathrm{R}}=304.6 \mathrm{~K}$ $\left(31.4^{\circ} \mathrm{C}\right)$ is a reference temperature (the intercept of the $A \leftarrow M^{+}$line at zero stress, also incidentally near $A_{\mathrm{s}}=$ $26^{\circ} \mathrm{C}$ ). This alloy was subjected by the manufacturer to $30 \%$ cold drawing followed by a $500^{\circ} \mathrm{C}$ anneal for $3 \mathrm{~min}$ (an extensive discussion of the metallurgy of NiTi can be found in ref. ${ }^{6}$ ). Drawn NiTi wire often has a strong $\left\langle\begin{array}{llll}1 & 1 & 1\end{array}\right\rangle$ crystallographic texture (in B2 axes for A), and the resolved uniaxial strain of an $M$ habit plane variant (at zero stress) is $\beta=0.05309$ (calculated from the data of refs. ${ }^{7,8}$, and shown in Fig. $2 \mathrm{c}$ by a dotted line). This calculation gives a theoretical value $\mathrm{d} \sigma / \mathrm{d} T=7.92 \mathrm{MPa} /{ }^{\circ} \mathrm{C}$, which is close to the measured value of $7.8 \mathrm{MPa} /{ }^{\circ} \mathrm{C}$. One might argue that equilibrium thermodynamics does not apply because the transformation is clearly hysteretic (irreversible), but such a good estimate, at least in a restricted temperature range, suggests that the actual stress-induced transformation occurs when the Gibb's energy difference between the two phases reaches a constant critical value, so the slope of the line is preserved. The effect of this is to just shift the line up for $A \rightarrow M^{+}$and down for $A \leftarrow M^{+}$from a theoretical (intermediate) equilibrium line $\left(A \leftrightarrow M^{+}\right)$. The intercepts of the fits at zero stress are $T_{0}^{A M^{+}}=-2.3^{\circ} \mathrm{C}$ and $T_{0}^{\mathrm{M}^{+} \mathrm{A}}=31.4^{\circ} \mathrm{C}$, respectively. Note that these are within about $5^{\circ} \mathrm{C}$ of $M_{\mathrm{s}}=-7^{\circ} \mathrm{C}$ and $A_{\mathrm{s}}=26^{\circ} \mathrm{C}$ as measured by DSC.

\section{Details of Shape Memory Wire Experiments}

Having introduced a material quasi-phase diagram and placed it in a simple thermodynamic framework, we now return to the four experiments of Fig. 1. The stress-strain curves shown before are conventional, but the plots have suppressed the important parameter of time $(t)$. Consequently, Fig. 3 shows the time histories of stress $(\sigma)$, global strain $(\delta / L)$, local strain $\left(\varepsilon_{\mathrm{e}}\right)$, and local temperature change $\left(\Delta T \equiv T-T_{\mathrm{a}}\right)$ for each of these experiments. Figure $3 \mathrm{a}$ and $\mathrm{b}$ is the respective water and air experiments at the slow rate $\dot{\delta} / L= \pm 4 \times 10^{-4} \mathrm{~s}^{-1}$, and Fig. $3 \mathrm{c}$ and $\mathrm{d}$ is the respective water and air experiments at the faster rate $\dot{\delta} / L= \pm 4 \times 10^{-2} \mathrm{~s}^{-1}$. The global strain $(\delta / L$, controlled and measured, shown by a thin line) in each case traces a ramp upward then a ramp downward until the stress reaches about zero (see the strain scale on the right).

Focusing on the first experiment shown in Fig. 3a, the stress history (scale on the left) during loading initially rises linearly while mostly elastic straining with a small growing nonlinearity above about $400 \mathrm{MPa}$ due to some early $A \rightarrow M^{+}$transformation (and some grip slippage at the stress concentrations at the grips). It reaches the upper plateau (576 MPa) with an essentially zero structural tangent modulus $(\dot{\sigma} /(\dot{\delta} / L) \approx 0$, to within minor stress fluctuations of about $\pm 5 \mathrm{MPa}$ ) during most of the $A \rightarrow M^{+}$ transformation. During subsequent unloading, the stress initially decreases steeply due to elastic strain recovery and then with a shallower slope probably due to some early $A \leftarrow M^{+}$transformation and possibly some re-twinning of $M$. The stress eventually reaches the lower plateau (298 \pm $5 \mathrm{MPa}$ ) for reverse $A \leftarrow M^{+}$transformation, and then when exhausted drops in a mostly linear fashion due to final elastic strain recovery of $A$. This stress history over about $310 \mathrm{~s} \mathrm{can}$ be imagined as an "unfolded" stress-elongation curve, since $\delta / L$ corresponds to a time-like parameter.

The local temperature change history as measured by the specimen thermocouple $(\Delta T)$ is interesting. It shows no temperature deviation from the ambient temperature (see the temperature scale on the right) for most of the experiment, except for a momentary rise of about $2^{\circ} \mathrm{C}$ midway through the loading stress plateau, and then a momentary drop of about $-1.5^{\circ} \mathrm{C}$ during the unloading stress plateau. Recalling from the DSC results of Part 1 that the $A \rightarrow M$ transformation is exothermic and the $A \leftarrow M$ is endothermic, one can now understand the reasons for the small temperature changes measured during the respective stressinduced transformations. They are small because the loading rate is slow and water is a relatively conductive/convective heat transfer medium, yet even water does not completely maintain isothermal conditions in the wire specimen at this loading rate. Thus, a $2^{\circ} \mathrm{C}$ temperature rise corresponds to a $7.8 \mathrm{MPa} /{ }^{\circ} \mathrm{C} \times 2^{\circ} \mathrm{C}=15.6 \mathrm{MPa}$ elevation from the true isothermal value of about $\sigma_{\mathrm{P}}^{A M^{+}}=560 \mathrm{MPa}$. Likewise, the $-1.5^{\circ} \mathrm{C}$ temperature change corresponds to a $-11.7 \mathrm{MPa}$ suppression of the unloading plateau from the true isothermal value of $310 \mathrm{MPa}$. Thus, at an ambient temperature of $70^{\circ} \mathrm{C}$ the experiment has a stress hysteresis (278 MPa) larger than the true isothermal hysteresis $(251 \mathrm{MPa})$ by about $27 \mathrm{MPa}$, an important consideration for the experimentalist trying to accurately obtain isothermal material responses. 
(a) Water, slow

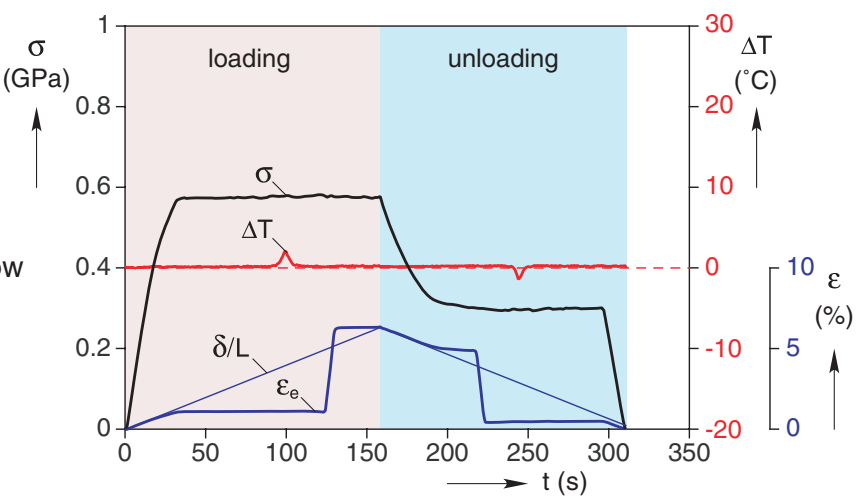

(b) Air, slow

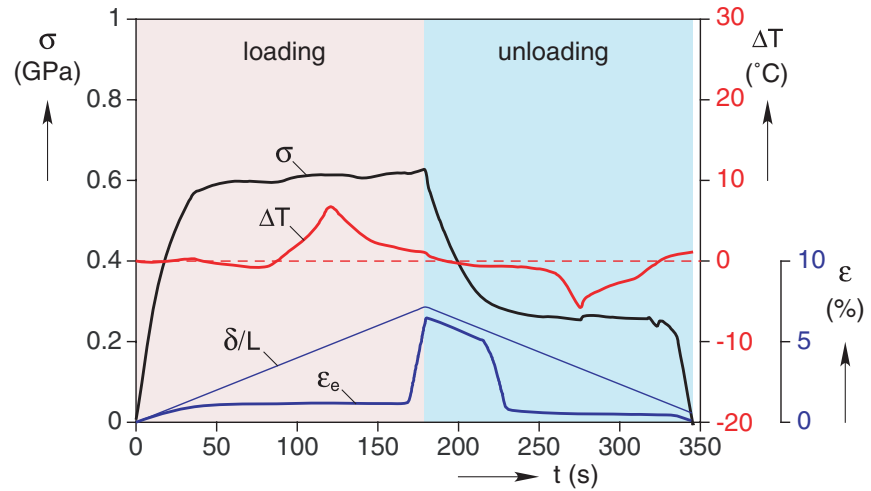

(c) Water, fast

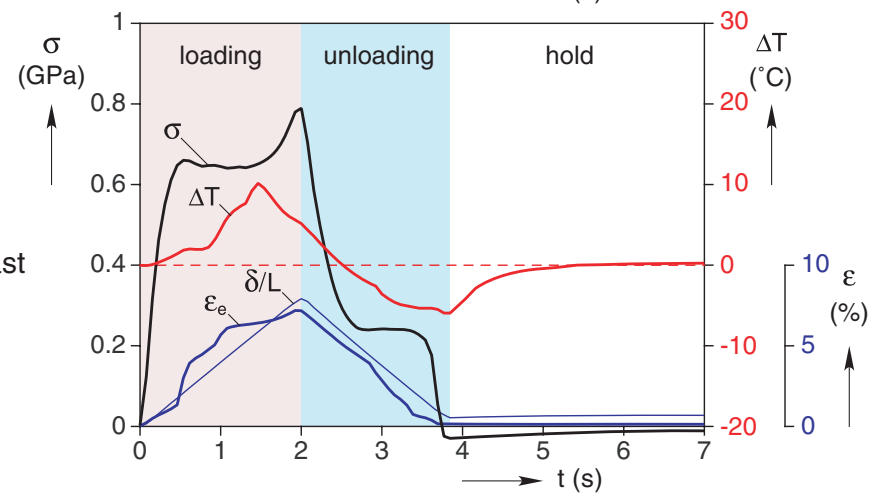

(d) Air, fast

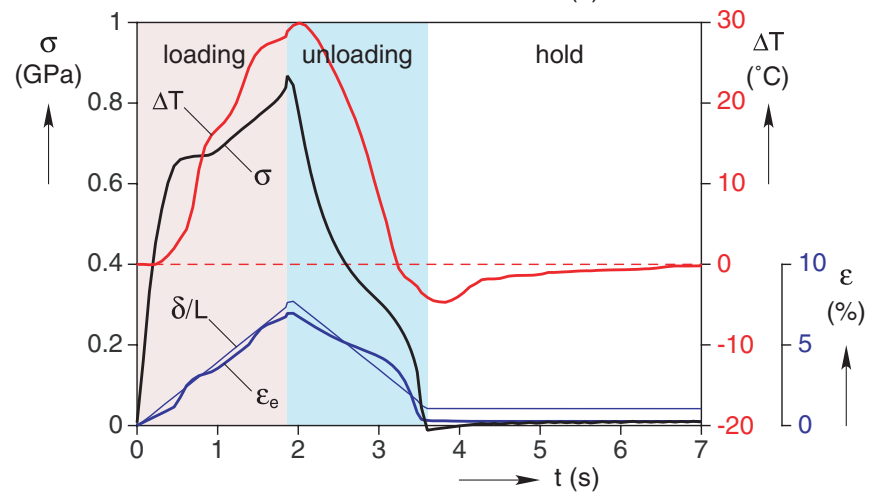

Fig. 3: Measurement histories for SM wire experiments of Fig. I: (a) and (b) $\dot{\delta} / L= \pm 4 \times 10^{-4} \mathrm{~s}^{-1}$; (c) and (d) $\dot{\delta} / L= \pm 4 \times 10^{-2} \mathrm{~s}^{-1}$ 
The last measurement history shown for this experiment is the local strain $\left(\varepsilon_{\mathrm{e}}\right)$. Initially, the local strain tracks along the global strain ramp during the steeply rising portion of the stress history, but within the loading stress plateau, the local strain change is limited to a sudden rapid increase just before the completion of the plateau. The near step jump in the strain history gives a clear indication of the plateau strain, and picking off the endpoints of the jump was the method used to plot their difference in Fig. 2c. At the end of the stress plateau, the local and global strain measures agree once again, since this experiment suffered very little grip slippage (thanks to newly machined grips). During unloading there is similar behavior, as the local strain history first tracks downward along the global strain history, but diverges from the global one during the lower stress plateau in a downward stepwise fashion.

Accordingly, the jumps in the local strain history and the momentary peaks in the specimen temperatures suggest that most of the transformations occur in a localized manner through the motion of transformation fronts, rather than occurring gradually in a uniform way. This is consistent with the localized transformation behavior discussed in Part 3 previously, and was, in fact, how the phenomena was discovered in ref. ${ }^{5}$. The times when transformations are detected, of course, depend on the placement of the extensometer and thermocouple along the specimen and the motion of transformation fronts.

Looking at the second experiment shown in Fig 3b, we see a similar behavior in the air experiment at the same slow loading rate. Now, the upper stress plateau is wavier in the range $611 \pm 18 \mathrm{MPa}$, and the lower plateau is in the range $257 \pm 14 \mathrm{MPa}$ with a few small stress disturbances that are related to the nucleation or coalescence of $A \leftarrow M^{+}$ transformation fronts (as shown in Section on SE Wire Experiments in Room Temperature Air). The temperature excursions measured by the thermocouple are larger and broader in time, indicating that more axial thermal conduction exists along the wire as a front passes the thermocouple location. The temperature rise during the $A \rightarrow M^{+}$stress plateau is $4.3^{\circ} \mathrm{C}$ and the temperature decrease during the $A \leftarrow M^{+}$stress plateau is $-4.8^{\circ} \mathrm{C}$, which is the reason for the elevated and then suppressed stress plateaus compared with the case in water. Obviously, air is not as conductive/convective as water, resulting in larger temperature excursions during the forward and reverse transformations as latent heat is released (loading) then absorbed (unloading) in the specimen. The strain history is similar to the water experiment except that the local strain jump occurs late in the $A \rightarrow M^{+}$transformation during loading and then early in the $A \leftarrow M^{+}$transformation during unloading. Also, the extensometer strain and global strain measures are offset somewhat due to some grip slippage that occurred near the onset of $A \rightarrow M^{+}$transformation in this experiment, so clearly the global strain is an artificially high measure of the actual residual strain at the end of the experiment. The final residual strain according to the extensometer is $0.07 \%$.

Proceeding to the third experiment (water) histories in Fig. 3c, one should first note the shorter time scale consistent with the faster $(100 \times)$ loading-unloading rate. In this case, the prescribed elongation history $(\delta / L)$ is a ramp upward for about $2 \mathrm{~s}$, ramp downward for just under $2 \mathrm{~s}$, then a hold for about $3 \mathrm{~s}$. During loading, the stress history rises to a local maximum at $660 \mathrm{MPa}$ during early $A \rightarrow M^{+}$transformation, which relaxes to a local minimum of $641 \mathrm{MPa}$ before rising again to the maximum stress of $789 \mathrm{MPa}$ at the maximum elongation. During unloading, the stress drops rapidly until it reaches the lower plateau of $240 \pm 3 \mathrm{MPa}$, then finally drops steeply again to $-25 \mathrm{MPa}$ (which likely caused some buckling of the wire) when the grip displacement stopped. During the hold, the stress rises somewhat to a steady state value of $-11 \mathrm{MPa}$. During loading, the thermocouple records a temperature change in the specimen that rises initially and plateaus momentarily to about $\Delta T=2.2^{\circ} \mathrm{C}$, then rises steeply to a maximum of about $10.2^{\circ} \mathrm{C}$ before decreasing. Note that the temperature is still elevated above the ambient temperature by about $5.2^{\circ} \mathrm{C}$ when unloading is started. The temperature continues to drop during unloading until it reaches $\Delta T=-6^{\circ} \mathrm{C}$ (subambient) when the grip motion stops. During the hold, the temperature rises asymptotically back to the ambient temperature and some transformation continues to occur, which is the reason for the slight rise in stress during this time. The extensometer history during the loading stress plateau rises in a stop-start manner, somewhat reminiscent (but less distinctly so) to the step jumps seen in the slower experiments. During unloading, it generally follows the downward trend of the global strain with some minor waviness, and the final residual strain is $0.13 \%$.

Finally, observe the histories in the fourth experiment shown in Fig. 3d for the faster rate in air. During loading, the stress history rises to the upper plateau of about $667 \pm 7 \mathrm{MPa}$ during early $A \rightarrow M^{+}$transformation before rising more steeply after $1 \mathrm{~s}$ to the maximum stress of $868 \mathrm{MPa}$. During this time period, the thermocouple records a generally rising specimen temperature change to about $\Delta T=28^{\circ} \mathrm{C}$ at the maximum strain. Interestingly, upon unloading the temperature continues to rise to a local maximum of $\Delta T=30^{\circ} \mathrm{C}$ before dropping steeply during the remainder of unloading. The stress history drops in a nonlinear way without any plateau, just decreasing at a somewhat slower rate during the time interval of most rapid reverse transformation. The stress became slightly negative (-11.8 $\mathrm{MPa}$ ) at the end of unloading when the grip displacement stopped, but subsequently rose asymptotically to a slight positive value $(11 \mathrm{MPa})$ during the hold. This indicates that some minor reverse transformation continued to occur during the hold that created slight tension in the specimen under fixed end conditions. The minimum specimen temperature $\left(\Delta T=-4.7^{\circ} \mathrm{C}\right)$ was actually reached slightly after the grip motion stopped, and the temperature eventually rose back to ambient temperature during the hold.

\section{Another Slightly Different Experiment}

We just showed that the temperature may continue to change even after the direction of cross-head motion is changed or stopped. For comparison, Fig. 4 presents another experiment in air at the faster rate, $\dot{\delta} / L= \pm 4 \times 10^{-4} \mathrm{~s}^{-1}$, where the experiment was changed slightly, pausing (elongation held fixed) between loading and unloading. The relaxation rates during the two holds (stress decay and rise) can be analyzed to obtain a sense of the time constants involved. 


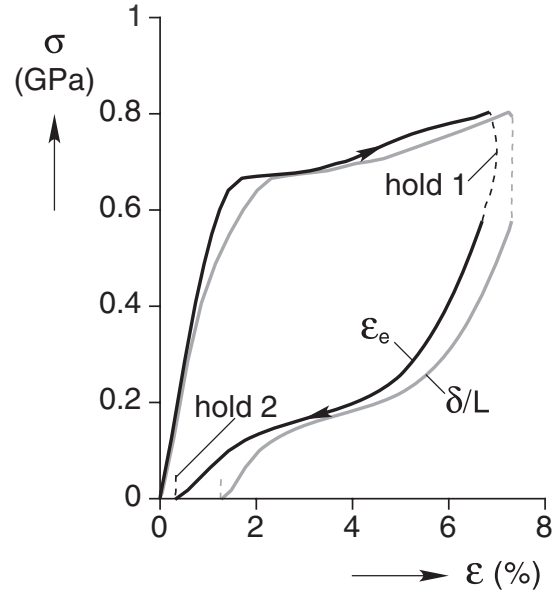

(a)

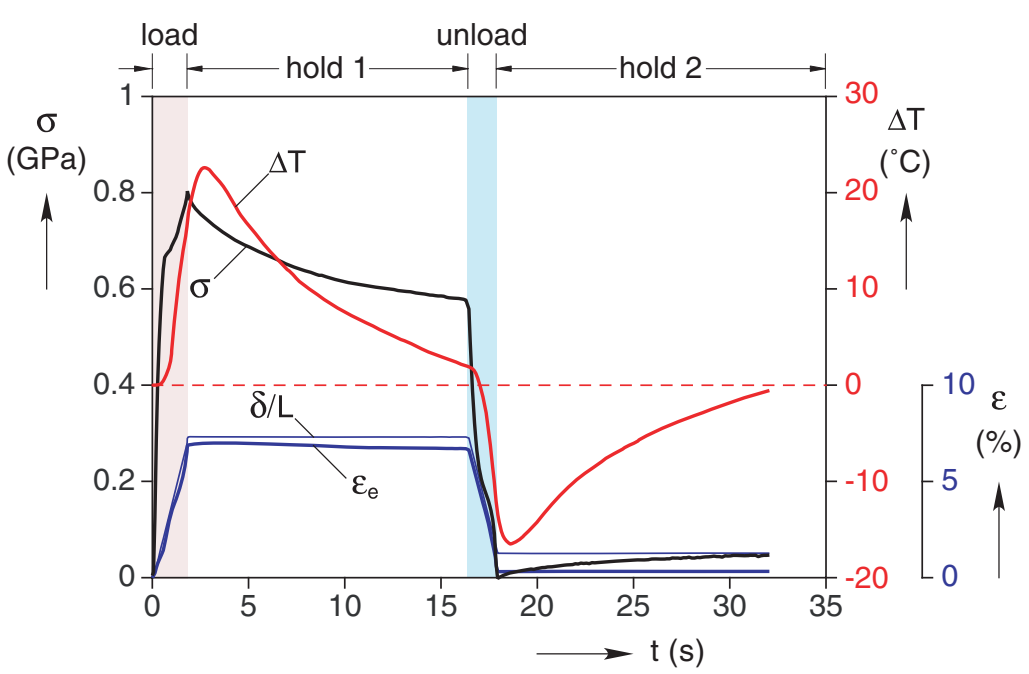

(b)

Fig. 4: Experiment on $S M$ wire in $70^{\circ} \mathrm{C}$ air at $\dot{\delta} / L= \pm 4 \times 10^{-2} \mathrm{~s}^{-1}$ with elongation holds after loading and unloading: (a) mechanical response (black line based on extensometer, gray line based on grip displacement) and (b) measurement histories

The mechanical response is shown in Fig. 4a (black line is based on the local extensometer strain, gray line is based on the global strain between the grips) and the measurement histories are shown in Fig. 4b. The elongation was ramped upward for $1.83 \mathrm{~s}$ to $\delta / L=7.3 \%$, held fixed for about $14.5 \mathrm{~s}$ ramped downward for $1.51 \mathrm{~s}$ and then held fixed for another $14 \mathrm{~s}$. This is a small change in experimental procedure from the air experiment of Fig. 1b (also Fig. 3d), so it is interesting to compare the two results. The responses of Fig. $4 \mathrm{a}$ and the air case in Fig. 1b are similar during loading (as would be expected), but (Fig. 4a) exhibits a larger stress hysteresis by suppressing the unloading response downward in stress.

As shown in Fig. 4b, the knee in the stress history during the loading ramp started at about $665 \mathrm{MPa}(0.58 \mathrm{~s})$ and then reached a maximum stress of $803 \mathrm{MPa}$ near the maximum elongation $(1.83 \mathrm{~s})$. The stress decayed to $576 \mathrm{MPa}$ by the end of the hold $(16.4 \mathrm{~s})$. During the hold, the extensometer strain rose slightly from $6.89 \%(1.83 \mathrm{~s})$ to $7.00 \%(3.41 \mathrm{~s})$ before settling downward to $6.76 \%$ (10.6 s). During the unload ramp, the stress dropped in a nonlinear way, more slowly around $200 \mathrm{MPa}$, until the cross-head was held when the stress had reached $-1.5 \mathrm{MPa}$. During the second hold, the stress grew somewhat, finally settling near $47 \mathrm{MPa}$. Both stress relaxation sets can be fit well with an exponential function (see Fig. 5) of the form

$$
\sigma(t)=\Delta \sigma_{0} \mathrm{e}^{-\left(t-t_{0}\right) / \tau}+\sigma_{\infty},
$$

where $\Delta \sigma_{0}, \sigma_{\infty}$, and $\tau$ are fitting parameters, and $t_{0}$ is a known time. The time constants are $\tau=6.04 \mathrm{~s}$ for the stress decay during the first hold and $\tau=6.36 \mathrm{~s}$ for the stress rise during the second hold. Of course, these are not universal constants. They depend on whether the air is stagnant or

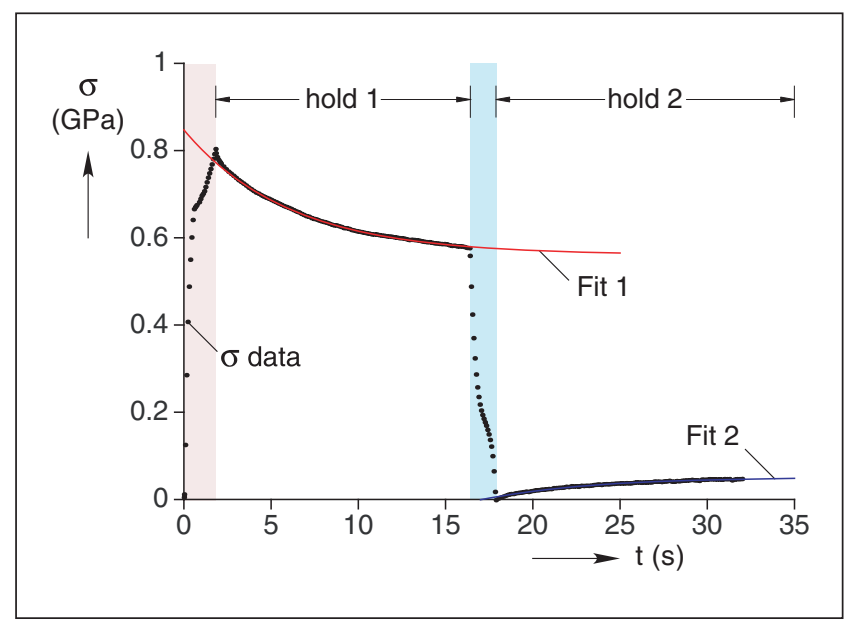

Fig. 5: Exponential fits of stress relaxations during the two hold times

blowing, the orientation of the wire (ours is vertical) to any prevailing air velocity, the diameter and length of the wire, and the particular thermal boundary conditions at the grips. Based on a lumped model of the wire ${ }^{9}$ (uniform transformation with insulated ends), the approximate convective film coefficient can be found from $\tau=\rho c_{0} l^{*} / h=6 \mathrm{~s}$ based on a characteristic length of $l^{*}=d / 4$, giving $h \approx 130 \mathrm{~W} /\left(\mathrm{m}^{2} \mathrm{~K}\right)$.

Returning to Fig. 4b, the temperature rise in the specimen at the thermocouple during the load ramp was $18^{\circ} \mathrm{C}$ at $t=1.83 \mathrm{~s}$, which reached a maximum shortly thereafter at $\Delta T_{\max }=22.6^{\circ} \mathrm{C}(2.7 \mathrm{~s})$. The temperature subsequently 
decayed during the hold, reaching $\Delta T=1.9^{\circ} \mathrm{C}$ at the end of the hold. Note that the time interval over which it decayed $(14 \mathrm{~s})$ was much longer than the time for a similar drop in temperature (about $1 \mathrm{~s}$ ) in the air experiment of Fig. 3d. That experiment (without the pause) had not only the ambient air temperature, but the reverse transformation driving the temperature downward. Fitting a similar exponential function $\Delta T(t)=\Delta T_{1} \mathrm{e}^{-\left(t-t_{1}\right) / \tau}$ to a portion of the decreasing temperature data of Fig. $4 \mathrm{~b}$ gives a time constant of about $\tau=6.2 \mathrm{~s}$. Although this agrees well with the stress relaxation time constant, one should be wary of making strong conclusions. We got lucky. Here, unlike the stress (which is uniform according to mechanical equilibrium), the temperature field is spatially nonuniform. In other words, the agreement might not be as good if the thermocouple had been placed somewhere else. In fact, at the start of the hold, the temperature at the thermocouple location was rising, whereas the stress was decreasing! It indicates that some additional $A \rightarrow M^{+}$ transformation occurred early in the hold (also consistent with the small increase in extensometer strain recorded) and/or temperature gradients may have existed that resulted in a redistribution of the temperature field toward thermal equilibrium (allowing the possibility of a rising temperature at some particular location). During the unloading ramp, the thermocouple temperature dropped $\left(\Delta T=-13.4^{\circ} \mathrm{C}\right)$ by the ramp's end ( $17.9 \mathrm{~s})$. It continued to decrease during the hold until reaching a minimum of $\Delta T=-16.5^{\circ} \mathrm{C}(18.5 \mathrm{~s})$ before turning around to rise exponentially, mirroring the temperature history during the first hold, that is, upside-down trends.

\section{Not Your Usual Viscoplasticity}

Although some modeling work has treated the observed SMA loading-rate dependence as temperature-dependent viscoelastic or viscoplastic phenomena, we hope that you are now convinced that loading rate effects are predominantly due to the inherent temperature sensitivity of the transformation stresses and the release/absorption of latent heat that causes self-heating/self-cooling of the SMA. Clearly, the ambient media sensitivities are not just the usual viscoelastic effects as would be seen in polymeric materials ${ }^{10}$ or viscoplastic effects seen in metals ${ }^{11}$ (usually at much higher rates). As a result, the amount of loading-rate sensitivity is strongly sensitive to the prevailing heat transfer conditions, that is, the effective film coefficient for lateral heat transfer $(h)$, for the temperature bath, the thermal conductivity of the wire $(K)$, and the thermal boundary conditions (from heat sinks to insulated ends).

Furthermore, there is a geometric dependence. Because the heat source is internal to the SMA material, it scales with the material volume; whereas, the lateral heat transfer (that extracts/supplies most of the latent heat generated/absorbed in a long, thin wire) scales with the exterior surface area of the SMA. By a simple analysis, the internal heat rate is $\dot{Q}_{\Lambda}=\rho V \Lambda \dot{\xi}$, where $\rho$ is the SMA mass density, $V=$ $\pi d^{2} \Delta x / 4$ is the volume of a cylindrical segment of material, $\Lambda$ is the latent heat (i.e., enthalpy change for $M \rightarrow A$ at constant stress) for the particular phase transformation, and $\xi \in[0,1]$ is the $M$ phase mass fraction. The radial heat transfer rate from the specimen is $\dot{Q}_{\mathrm{R}}=h A_{\mathrm{S}}\left(T-T_{\mathrm{a}}\right.$ ), where $A_{\mathrm{S}}=\pi d \Delta x$ is the surface area of the cylinder. Ignoring axial thermal conduction for now and equating gives the steady state temperature rise of

$$
\Delta T_{\mathrm{ss}}=\frac{\rho \Lambda \dot{\xi}}{h} \frac{d}{4} .
$$

The rate of phase transformation $\dot{\xi}$ is related to the rate of straining, $\dot{\delta} / L$ (and at constant stress is proportional). Thus, for a given ambient medium (fixing $h$ ) and loading rate (fixing $\dot{\xi}$ ), the temperature change will be larger in magnitude for a larger diameter wire, and $l^{*}=V / A_{\mathrm{S}}=d / 4$ plays the role of a characteristic length. Accordingly, the stress required for transformation will change by a larger amount.

Two extremes in the response should be distinguished: the isothermal response arising at slow loading rates in convective/conductive media, versus the adiabatic response arising at moderately fast loading rates in a thermally insulating medium. In practice, therefore, the response measured in laboratory (tightly controlled) conditions may be different than in-field applications if heat transfer conditions are different. So how large can the temperature change get? One can estimate the maximum temperature rise for adiabatic conditions from the specific heat $\left(c_{0}=0.45 \mathrm{~J} /(\mathrm{g} \mathrm{K})\right)$ and latent heat $\left(\Lambda^{M \rightarrow A}\right)$ as $\Delta T_{\max }=-\Lambda^{M \rightarrow A} / c_{0} \approx 43.6^{\circ} \mathrm{C}$. This gives a stress rise of about $234 \mathrm{MPa}$, predicting a $A \rightarrow M^{+}$transformation stress (starting at $70^{\circ} \mathrm{C}$ of $560+234=794 \mathrm{MPa}$ if the transformation occurred uniformly in vacuum with no axial heat conduction). The $20-30^{\circ} \mathrm{C}$ temperature rise at the thermocouple for the highest load rate in air is a significant fraction of this limiting value, and the stress maximum stress levels measured were actually larger than $794 \mathrm{MPa}$ (803-868 MPa), indicating near adiabatic conditions. Even larger local temperatures than the uniform adiabatic value are possible if the heat source is nonuniform, such as when two point sources (transformation fronts) approach each other (see the thermal analysis in ref. ${ }^{12}$ ).

\section{SUPERELASTIC WIRE EXPERIMENTS IN ROOM TEMPERATURE AIR}

The room temperature superelastic alloy (SE wire) provides the opportunity for infrared (IR) imaging, so we now present experiments on that material over a range of loading rates in air to study the details of transformation kinetics. This wire is somewhat thinner than the SM wire, having a diameter of $0.762 \mathrm{~mm}$, and the latent heat $\left(\Lambda^{M \rightarrow A}=15 \mathrm{~J} / \mathrm{g}\right)$ for this alloy is less than the SM wire.

First, the set of isothermal responses introduced in Part 2, but in a superelastic temperature window, are briefly reviewed for the SE wire. Plateau stresses and plateau strains were obtained by experiments on specimens with a free length of about $60 \mathrm{~mm}$ in a temperature-controlled air chamber at the very slow rate of $\dot{\delta} / L= \pm 5 \times 10^{-5} \mathrm{~s}^{-1}$ to avoid latent heat effects. Other experiments were performed using the thermoelectric/conduction block setup as discussed in Part $3^{3}$ to obtain the nucleation stresses (onset of localized transformation). Both the plateau stresses (filled circles) and nucleation stresses (open circles) are plotted in Fig. 6a, and a magnified view near room temperature is shown in Fig. 6b. Using Eq. (1) for the SE wire with a chosen reference temperature of $T_{\mathrm{R}}=-10^{\circ} \mathrm{C}$, gives a theoretical 


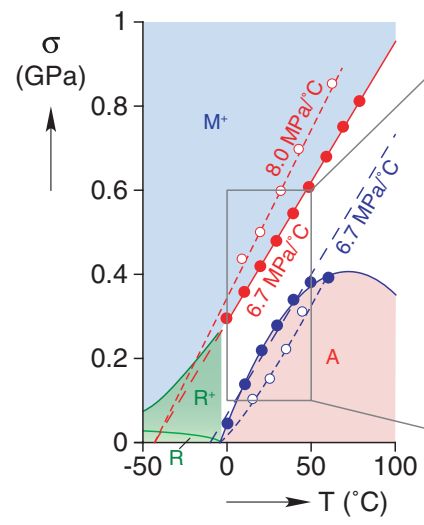

(a)

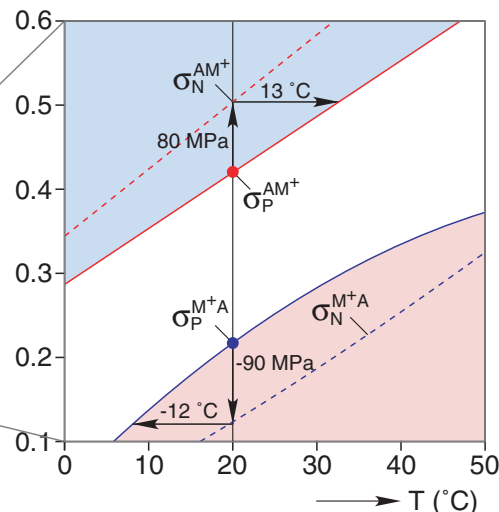

(b)

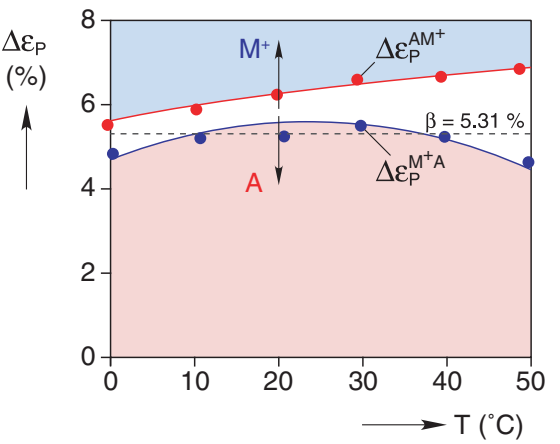

(c)

Fig. 6: Characteristic stresses and strains versus temperature for SE wire in the superelastic range: (a) plateau stresses (filled circles) and nucleation stresses (open circles), (b) magnified view near room temperature (20 ${ }^{\circ} \mathrm{C}$ ), and (c) plateau strains. Data were replotted from refs. ${ }^{2,3}$ with uncertainties approximately the size of the data symbols shown

Clausius-Clapeyron slope of $\mathrm{d} \sigma_{\mathrm{P}} / \mathrm{d} T=6.98 \mathrm{MPa} /{ }^{\circ} \mathrm{C}$, which is reasonably close to the fitted line shown at $6.7 \mathrm{MPa} /{ }^{\circ} \mathrm{C}$. The superelastic stress hysteresis is somewhat less for this alloy $\left(203 \mathrm{MPa}\right.$ at $\left.20^{\circ} \mathrm{C}\right)$ than for the $\mathrm{SM}$ wire $\left(251 \mathrm{MPa}\right.$ at $\left.70^{\circ} \mathrm{C}\right)$. Both sets of plateau strains are plotted in Fig. 6c, showing similar trends to that of the SM wire, but at somewhat higher strains overall.

Now we turn to the loading-rate sensitivity of the SE wire in air. A series of five experiments in room temperature air (about $21^{\circ} \mathrm{C}$ ) were performed on the SE NiTi wire at elongation rates from $\dot{\delta} / L= \pm 1 \times 10^{-5} \mathrm{~s}^{-1}$ to $\dot{\delta} / L= \pm 1 \times$ $10^{-1} \mathrm{~s}^{-1}$ with no pause between loading and unloading. The wire was held between flat-plate grips, in which the lower one was fixed and the upper one moved with the testing machine cross-head. The free length of the specimen in these cases was short, about $33.3 \mathrm{~mm}$, to give a better field of view for IR imaging. Figure 7 shows mechanical responses from all five experiments, which have similarities to those from the SM wire in Fig. 1. Here the strain measurement was obtained from a laser extensometer (as discussed in Part 2) with two retro-reflective tags glued to the specimen. The tags were positioned roughly $20 \mathrm{~mm}$ aPart and well away

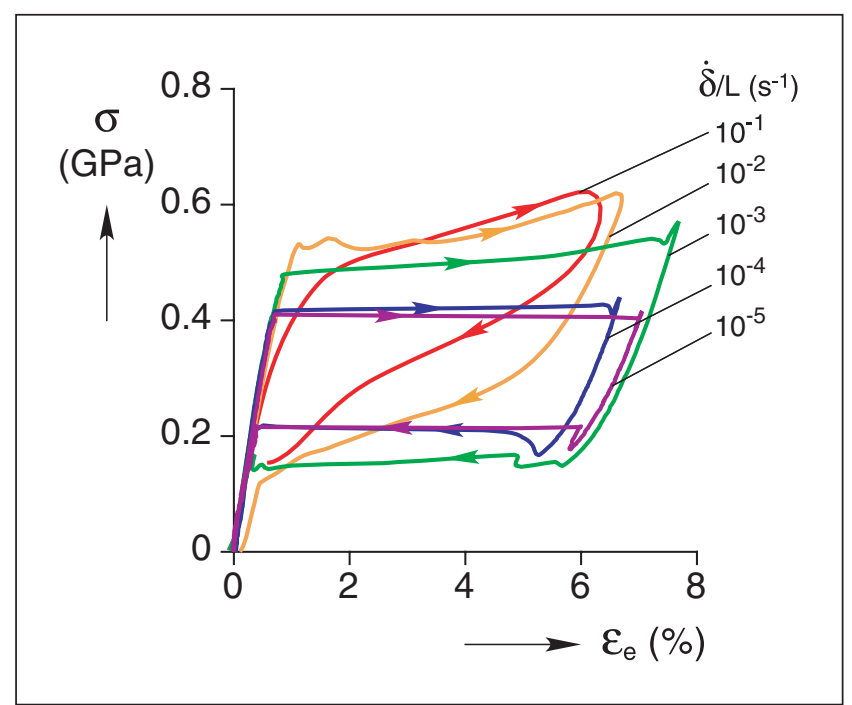

Fig. 7: Mechanical responses of SE wire at five loading rates in room temperature $\left(21 \pm 0.7^{\circ} \mathrm{C}\right)$ air 
from the grips to avoid artifacts from the inevitable stress concentrations and possible grip slippage. Each experiment was performed on a fresh specimen from the same spool of material.

The lowest rate experiment was performed at the extremely slow rate of $\dot{\delta} / L= \pm 1 \times 10^{-5} \mathrm{~s}^{-1}$. The stress plateaus for both $A \rightarrow M^{+}$and $A \leftarrow M^{+}$were quite flat at $408 \pm 4 \mathrm{MPa}$ (actually decreasing slightly) and $215 \pm 1 \mathrm{MPa}$, respectively. At $\dot{\delta} / L= \pm 1 \times 10^{-4} \mathrm{~s}^{-1}$, the response was similar, although the loading plateau had a slight positive slope and ended $15 \mathrm{MPa}$ higher than the lowest rate. Progressively higher rate experiments exhibit larger slopes during transformation and larger maximum stresses. The size of the stress hysteresis changed nonmonotonically with loading rate, starting small and growing up to the $\dot{\delta} / L=1 \times 10^{-3} \mathrm{~s}^{-1}$ case and then decreasing at higher rates as the response became more adiabatic. Because SMAs are being envisioned as damping elements under oscillatory motion, this behavior is worth noting since the trends may be unexpected. We should also mention that the highest rate experiment, $\dot{\delta} / L=1 \times 10^{-1} \mathrm{~s}^{-1}$, which only took about $1.5 \mathrm{~s}$ for the entire load-unload cycle, is less accurate than the others. It was performed near the limits of the load frame (which did not precisely track the command ramps due to some backlash) and data acquisition filter, so while the mechanical results shown are imperfect and should only be viewed qualitatively, the IR imaging results shown below are interesting and transformations of this sort have not been seen before to the best of our knowledge.

\section{Front Tracking by Infrared Imaging}

For each experiment, an IR imaging system (model SC1000 with a $256 \times 256$ pixel array, from Inframetrics, now FLIR, Boston, MA) was used to record the temperature of the front face of the wire. IR imaging on a specimen with such a high aspect ratio $(L / d \approx 44)$ and from a nonplanar (cylindrical) surface is challenging. It required careful alignment and subpixel interpolation to obtain accurate wire temperatures. It also required accurate measurement of the emissivity of the specimen surface, $\epsilon=0.66$ in our case. Although not done at the time of these experiments, we now commonly lightly spray paint on our specimens (high temperature Rust-Oleum matte paint works well) to improve the emissivity to $\epsilon \approx 0.95$ to reduce unwanted IR reflection of background radiation and to avoid issues associated with variable surface finishes of different wire batches.

Recall from Part 3 that stress-induced transformations in "virgin" NiTi wire may localize, rather than occur homogeneously throughout the specimen length. The phases segregate into nearly disjoint axial regions rather than mixing at a finer scale. Phase localization, that is, nucleation of a new phase in an autocatalytic manner across the entire wire diameter, can cause abrupt drops in load as an axial inclusion of $M^{+}$suddenly develops in a uniform $A$ region, or can cause sudden rises in load as an axial inclusion of $A$ develops in a uniform $M^{+}$region. Nucleation of $M^{+}$causes a sudden lengthening of a finite region (on the order of a few wire diameters), and since this happens quickly, the remainder of the wire unloads to maintain compatibility with the overall prescribed elongation. Conversely, nucleation of $A$ in a homogeneous region of $\mathrm{M}^{+}$causes a sudden shortening of a similar sized region that causes elastic straining (increased tension) in the rest of the wire to maintain compatibility (see also ref. ${ }^{13}$ for a detailed study of these nucleation events). These are unstable, that is, dynamic events that cannot be controlled even in elongation control, and of course, in load control the situation is even worse.

After a new phase nucleates, the region typically grows in axial extent consistent with the elongation rate. This forms two boundaries, or transformation fronts, on either side of the nucleated region. Each transformation front, viewed from afar, appears as a step discontinuity in strain. If one looks closer it is actually a deformation neck with a steep strain gradient, having a length scale of the wire diameter, since lateral strain compatibility due to Poisson effects must also be preserved (thereby disallowing any radial strain jumps). Nevertheless, we will take the first view, in the interest of simplicity, that treats the front as a near strain discontinuity. As the front transits along the wire axis, therefore, only the region near the front is actively transforming and releasing/absorbing latent heat. Because transformation occurs almost exclusively at these localized fronts, they can be considered point sources (or sinks) of heat where the local heat rate is related to the speed of each front. Thus, IR imaging will be used to track the location of transformation fronts, and any nucleation events, by monitoring the temperature changes caused by these heat sources and sinks.

Figure 8 shows an IR snapshot of a time instant of the experiment at $\dot{\delta} / L= \pm 1 \times 10^{-3} \mathrm{~s}^{-1}$. A schematic of the specimen with its laser targets is shown in Fig. 8a, and the $26 \times 172$ pixel IR contour image of the front of the specimen is shown in Fig. $8 \mathrm{~b}$ along with its temperature legend on the right. The laser tags, clearly visible as rectangles at $x / L=0.2$ and $x / L=0.8$, have a lower emissivity than the wire specimen, so the measured temperature changes are not accurate (underpredicted) at those locations and should be disregarded. The image shows two $A \rightarrow M^{+}$exothermic fronts (hot spots along the wire, between the laser targets) that were traveling toward each other from either end. The plot above the image is the discrete pixel data of IR intensities at $x / L=0.66$ (across the upper hot spot). The data drop off from the peak at the wire crown due to the changing surface normal vectors across the wire diameter. The plot also shows a nonlinear fit of the data that was used to locate the crown of the wire for alignment purposes and to pick off the maximum value. The extracted axial temperature profile at this time instant, $T\left(x, t_{1}\right)$, is plotted in Fig. 8c, which shows two temperature peaks (each about $30.5^{\circ} \mathrm{C}$ ), a depressed temperature profile between them, and nearly linear temperature decreases to the specimen ends where the grips act as heat sinks. Based on the prior history of the fronts up to this time, one can construct a phase map as shown in Fig. 8d.

\section{Details of Superelastic Wire Experiments}

Thermal and mechanical responses from the lowest rate experiment, $\dot{\delta} / L= \pm 1 \times 10^{-5} \mathrm{~s}^{-1}$, are shown in Fig. 9. The plot in Fig. 9b shows a grayscale contour plot (see the temperature palette on the right) of the evolution of the wire crown 

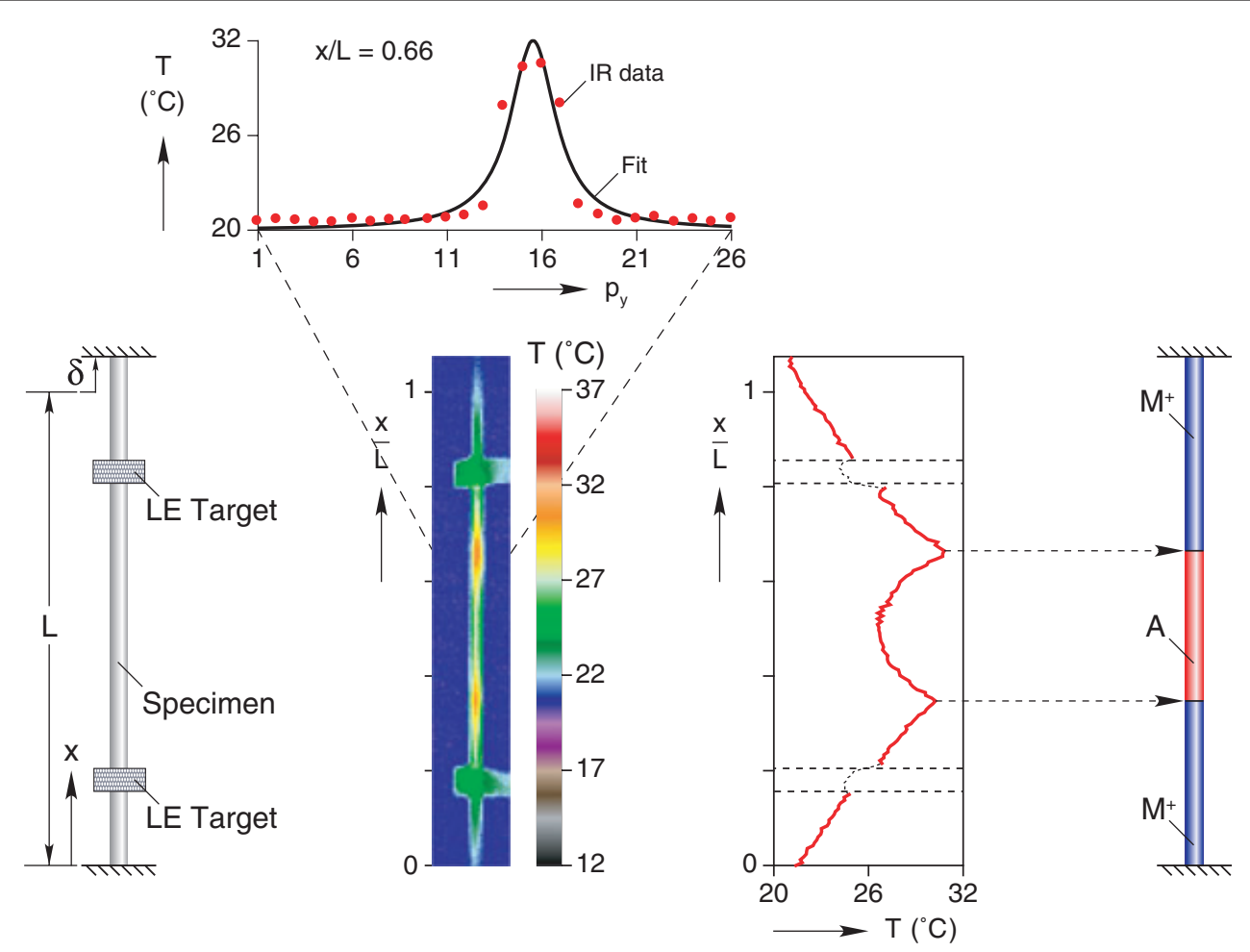

(a)

(b)

(c)

(d)

Fig. 8: IR imaging of SE wire: (a) specimen schematic, (b) example IR image showing two $A \rightarrow M^{+}$fronts between the laser extensometer target (from a time instant during the $\dot{\delta} / L= \pm I \times 10^{-3} \mathrm{~s}^{-1}$ experiment of Fig. I I below). Plotted above it is an example lateral profile at $x / L=0.66$ of IR temperature data across the 26 pixel image width. (c) Axial temperature profile along the wire crown and (d) phase distribution schematic

temperature $T^{\mathrm{IR}}(x, t)$ versus normalized distance along the wire $(x / L)$ and time $(t)$. This was constructed by laying sideby-side 864 vertical IR snapshots of the specimen (each one pixel wide) taken at $100 \mathrm{~s}$ intervals, synchronizing them in time, and then cropping them over the time period of the experiment. The upper edge of the images was also cropped at the moving upper grip location, thereby showing the grip motion $(\delta / L)$ in scale with the initial specimen length. The stress history $\sigma$ (dark black line) is overlaid according to the vertical scale on the right. The plot above it (Fig. 9a) shows the histories of global strain $(\delta / L)$ and gage-length strain from the laser extensometer $\left(\varepsilon_{\mathrm{e}}\right)$ according to the scale on the right, along with the IR temperature at the specimen's initial mid-span $\left(T_{\text {mid }}^{\mathrm{IR}}\right)$ according to the scale on the left. Important local events, such as a change in the number of transformation fronts or a front passing a laser tag, are marked on the contour plot by circles. Vertical lines point to the responses $\left(T, \varepsilon_{\mathrm{e}}\right.$, or $\left.\sigma\right)$ which are noticeably affected by the event. Other events, such as a change in cross-head velocity, are each marked by a vertical line only (no circle).

Of course, at this extremely slow rate one would not expect to observe much of a temperature change in the specimen, so the mid-line temperature history just shows minor fluctuations $\left( \pm 0.5^{\circ} \mathrm{C}\right)$ about a mean ambient temperature. Accordingly, the IR $x / L-t$ contour map is dominated by the artifacts from the laser tags (the dark horizontal streaks that, while inaccurate in temperature, provide useful markers to correlate with the $\varepsilon_{\mathrm{e}}$ history) and some minor fluctuations in the ambient temperature over the $>4.5 \mathrm{~h}$ experiment. Nevertheless, a barely observable temperature discontinuity (slightly lighter spots, higher $T$ ) appears during the upper stress plateau, moving from the lower end upward to the upper end in time. Likewise, a similar temperature discontinuity (now slightly darker spots, lower $T$ ) appears during the times of the lower stress plateau. Thus, a single $A \rightarrow M^{+}$front propagated at constant speed from bottom to top in the specimen, and then a single $A \leftarrow M^{+}$front propagated from top to bottom. This is confirmed by either sudden changes in the stress when fronts first appear or disappear, and by the kink discontinuities in $\varepsilon_{\mathrm{e}}$ that align (in time) with fronts crossing a laser tag. The derived phase plot is then shown in Fig. 9c, based on construction lines overlaid on the IR map.

There are a few features in the stress history (Fig. 9b) worth mentioning. As loading begins, the stress responded linearly, 


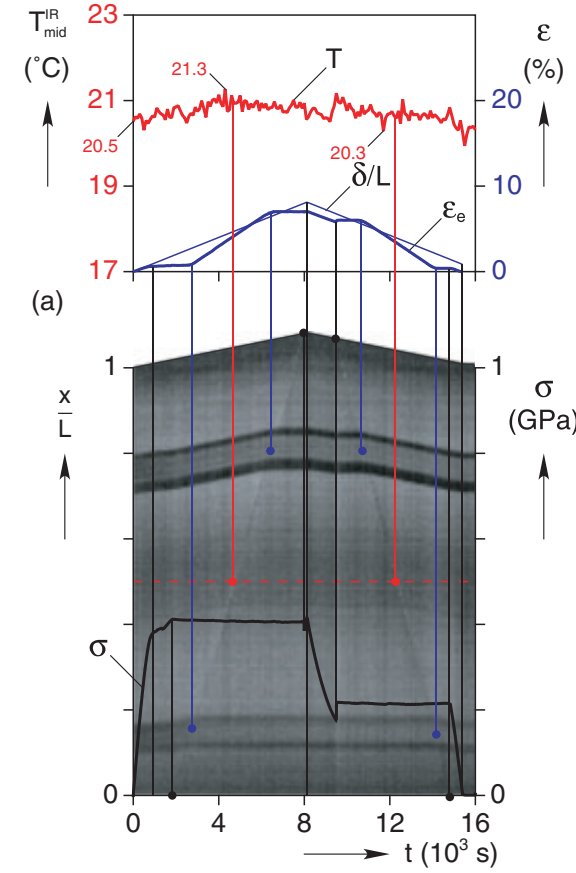

(b)

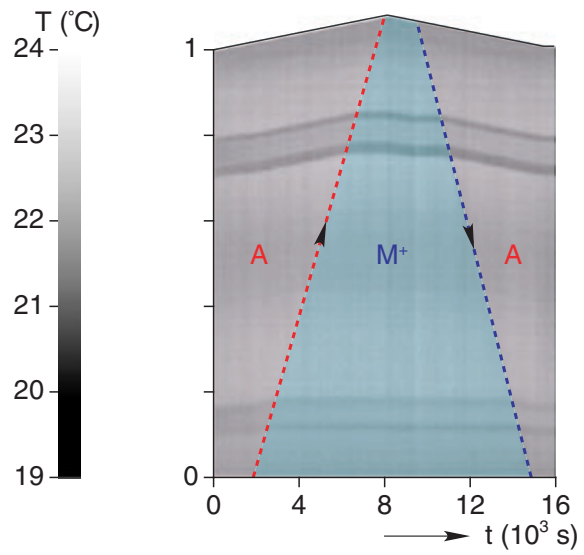

(c)

Fig. 9: Tensile experiment on SE wire in room temperature air at $\dot{\delta} / L= \pm I \times I 0^{-5} \mathrm{~s}^{-I}$ : (a) histories of global strain $(\delta / L)$, local strain $\left(\varepsilon_{\mathrm{e}}\right)$, and the IR temperature at the initial wire mid-span ( $T_{\text {mid }}^{I R}$ ); (b) IR grayscale contour map in space $(x / L)$ and time $(t)$ with stress history overlaid; and (c) derived phase map from a single $A \rightarrow M^{+}$front, then single $A \leftarrow M^{+}$front

increasing with time (and $\delta / L)$. At $t=800 \mathrm{~s}$, there was a knee in the stress response, probably because transformation had begun prematurely just inside the grips where a severe stress concentration (and multiaxial stress state) existed. This caused some slippage as the front (deformation neck) inch-wormed its way into the free length (this effect gets worse as the grip plate edges become worn with use, despite using hardened steel). At $1855 \mathrm{~s}$, the knee ends and the single transformation front emerged from the lower grip. Material below this front position was in the tensile martensite $\left(M^{+}\right)$phase, whereas the $A$ above it had yet to be transformed. Recall also from Part 3 that at a given temperature, transformation fronts propagate at a constant stress $\sigma_{\mathrm{P}}$, but must overcome a nucleation stress $\sigma_{\mathrm{N}}$ to form a new pair of fronts. In this experiment, one front stayed inside the lower grip, and with a nearly uniform temperature throughout the specimen, the elongation propagated a single front which never reached $\sigma_{\mathrm{N}}$ necessary to nucleate a new pair of fronts. At time $t=7992 \mathrm{~s}$, the front reached the upper grip, meeting another stationary front and there was a slight drop in stress $(-5 \mathrm{MPa})$ before rising again to the maximum stress (412 MPa) when the grip stopped.

The first dashed line in Fig. 9c marks the location of the single $A \rightarrow M^{+}$transformation front. Owing to compatibility requirements, the total rate of $M^{+}$production is determined by the prescribed grip-displacement rate $\dot{\delta}$. Because the grip rate was constant, the phase transformation rate during propagation was also constant, and the front speed $c$ can be related to the grip rate by

$$
c=\frac{\dot{\delta}}{n \Delta \varepsilon_{\mathrm{P}}},
$$

where $n$ is the number of fronts traveling in the specimen. This average front speed can be assumed constant for all fronts, provided each front experiences identical local temperature and stress conditions. In this experiment, there was only a single front $(n=1)$ and the $A \rightarrow M^{+}$transformation strain is measured as $6.25 \%$, so the front speed is calculated to be $c=5.33 \times 10^{-3} \mathrm{~mm} / \mathrm{s}$ and was measured here as $5.43 \times 10^{-3} \mathrm{~mm} / \mathrm{s}$.

Another way of stating this is to say that all fronts propagate at the same temperature, which is easily proven through a counter argument. Suppose two fronts could propagate at different temperatures, one hotter than the other. By the Clausius-Clapeyron relationship introduced in Part 3, the hotter front would also propagate at a higher stress. However, equilibrium requires that every point on the wire experience the same load (engineering stress). Therefore, actively propagating fronts cannot propagate at different temperatures. If one $A \rightarrow M^{+}$front gets momentarily hotter, its propagation stress will increase, causing it to slow down, generate less heat, and cool down to the temperature of the remaining fronts. Thus, the stress can be envisioned 


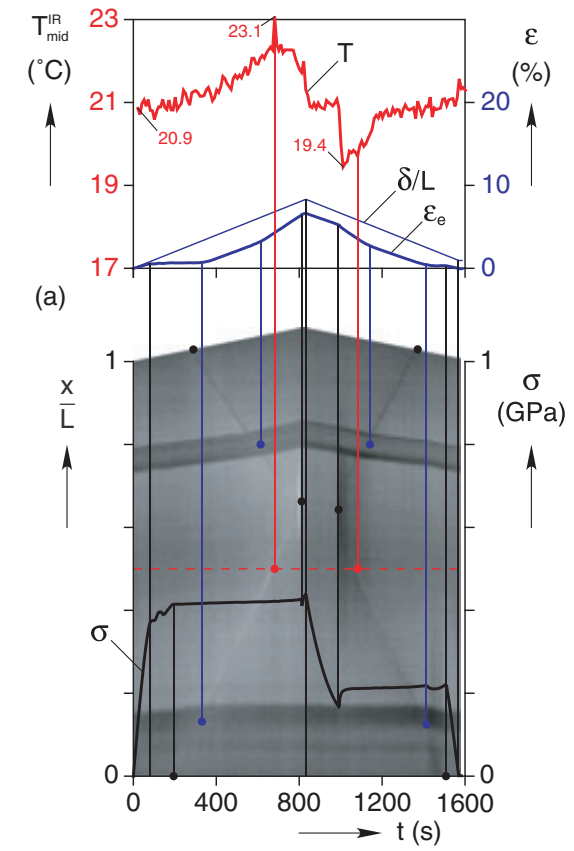

(b)

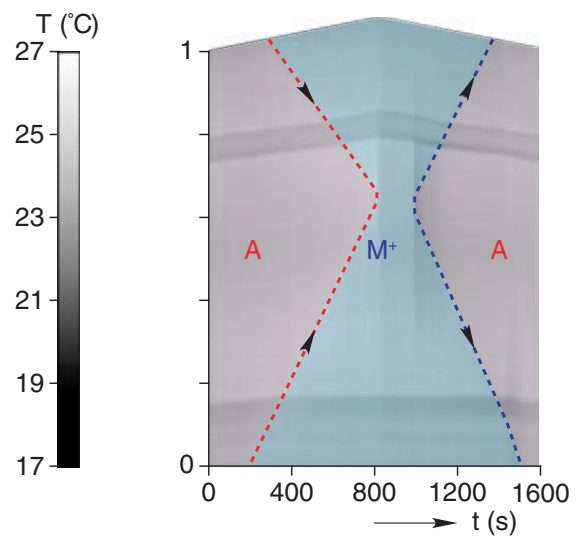

(c)

Fig. 10: Tensile experiment on SE wire in room temperature air at $\dot{\delta} / L= \pm I \times 10^{-4} \mathrm{~s}^{-1}$ : (a) histories of global strain $(\delta / L)$, local strain $\left(\varepsilon_{\mathrm{e}}\right)$, and the IR temperature at the initial wire mid-span ( $\left.T_{\text {mid }}^{\mathrm{IR}}\right)$; (b) IR grayscale contour map in space $(x / L)$ and time $(t)$ with stress history overlaid; and (c) derived phase map

as an indirect measure of the temperature of the actively transforming regions, provided fronts are far enough (at least a few wire diameters) away from each other that they do not mechanically interact (such as during nucleation or coalescence events).

Returning to the experiment shown in Fig. 10, transformation continued until the front reached the upper grip at $7992 \mathrm{~s}$, at which point the specimen was saturated with $\mathrm{M}^{+}$and the tangent modulus became positive again. Next, the grip reversed direction and the $M^{+}$unloaded with a steep modulus until the lower plateau. Because the stress concentrations at the grips tend to suppress the reverse transformation, $A \leftarrow M^{+}$nucleation was forced to occur somewhere in the gage length (in this case just below the upper grip). Recall that the unloading nucleation stress $\sigma_{\mathrm{N}}^{\mathrm{M}^{+} \mathrm{A}}$ is lower than the propagation stress $\sigma_{\mathrm{P}}^{M^{+} A}$, so stress rose suddenly following the $A$ nucleation at the top grip from a value of 175 to $218 \mathrm{MPa}$. At this point, a new front emerged near the upper grip at $9523 \mathrm{~s}$ and reached the bottom grip at $14,820 \mathrm{~s}$. This $M^{+} \rightarrow A$ front proceeded down the specimen at a constant stress, but slightly faster than the $A \rightarrow M^{+}$front, since the plateau strain is less. Using the unloading transformation strain of $5.59 \%$, the front speed predicted by Eq. (4) is $c=5.96 \times 10^{-3} \mathrm{~mm} / \mathrm{s}$ and the measured speed was $6.3 \times 10^{-3} \mathrm{~mm} / \mathrm{s}$. The reason the measured speeds are always somewhat higher than the theoretical values (by 1.9-5.7\% for the respective transformations) is that nucleation and coalescence events occur suddenly across a finite length of the specimen, so the fronts only propagated somewhat less distance than the full free length of wire. Thus, the measured values should be viewed as upper bounds. It was shown in ref. ${ }^{13}$ using a special setup that the nucleation region is about $2.7 d=2.06 \mathrm{~mm}$ for this wire near room temperature. Accounting for the coalescence event during $A \leftarrow M^{+}$and assuming this size of region during strain delocalization, the reduction in actual front travel is about $2.7 \times d / L=6.2 \%$ giving a corrected value of $5.91 \times 10^{-3} \mathrm{~mm} / \mathrm{s}$.

The second experiment used an order of magnitude greater that the loading rate, $\dot{\delta} / L= \pm 1 \times 10^{-4} \mathrm{~s}^{-1}$. The mechanical and thermal response is shown in Fig. 10, organized in the same manner as Fig. 9, but with a shorter time scale and larger temperature scale. The initial response was similar to the first experiment, with a small knee in the stress response as transformation began in the grips. A single front emerged from the lower grips at $191 \mathrm{~s}$ as the stress knee ended. A second front emerged from the upper grip at $275 \mathrm{~s}$ in the IR images, though the lack of any stress change with the event suggests that it had started at some earlier time within the upper grip, likely at $146 \mathrm{~s}$ when there was a small drop in stress. Both fronts were about $2{ }^{\circ} \mathrm{C}$ above ambient, evidenced by the peak in $T$ at $23.1^{\circ} \mathrm{C}$ as the lower front passed the centerline $(x / L=0.5)$. These two fronts proceeded toward each other at a constant rate of $2.8 \times 10^{-2} \mathrm{~mm} / \mathrm{s}$ (neglecting the murky issues at the grips), which is close to $c=$ $2.94 \times 10^{-2} \mathrm{~mm} / \mathrm{s}$, based on Eq. (4) and $\Delta \varepsilon_{\mathrm{P}}^{A M^{+}}=5.66 \%$ 
measured by the extensometer. As the two fronts got closer, their respective temperature fields interacted, so when they met at $809 \mathrm{~s}$, the maximum temperature rose to $5^{\circ} \mathrm{C}$ above ambient. It is typical to see this rapid change in temperature as two fronts coalesce, since for a brief moment the local rate of phase transformation doubles. This rise in temperature was also responsible for a corresponding rise in stress, evidenced by the slight positive slope of the stress plateau, which is easiest to see when compared with the $\dot{\delta} / L=1 \times 10^{-5} \mathrm{~s}^{-1}$ experiment shown in Fig. 7.

The unloading thermal history looks like an inverse (mirror) image of the loading history. There was a nucleation of $A$ at the same location where the two $A \rightarrow M^{+}$fronts coalesced, likely because the coalescence event caused a "knot" of incomplete transformation in the material (an imperfection) that served as a favorable nucleation site for $A \leftarrow M^{+}$. At this point there was a "burst" of heat absorption, lowering the temperature briefly about $4{ }^{\circ} \mathrm{C}$ below ambient. The two $M^{+} \rightarrow A$ fronts then moved aPart at a constant rate, as their temperature fields interacted less. At $1413 \mathrm{~s}$, the top front reached the upper grip. In keeping with Eq. (4), the lower front then doubled in speed, though the exact time is difficult to determine because the wire temperature in that area is obscured by the laser tag (dark streak). The stress dropped at the same time, since local self-cooling doubled with the speed, and also because the reflective target (attached with epoxy) had some insulating effect on the wire. This is an excellent example of the sensitivity of transformation kinetics to even minor experimental setup nonuniformities that can cause "mysterious" bumps in the mechanical response. At about $1508 \mathrm{~s}$, the bottom front reached the lower grip, completing the transformation.

The experiment shown in Fig. 11 shows the same front morphology during loading, at a rate another decade faster, $\dot{\delta} / L= \pm 1 \times 10^{-3} \mathrm{~s}^{-1}$. Two $A \rightarrow M^{+}$fronts emerged simultaneously from the upper and lower grips and propagated toward the specimen center at a constant rate but with greater self-heating (note the larger temperature scale used). As they pulled away from the thermally massive grips, they were able to heat up, the stress rising from 441 to $543 \mathrm{MPa}$. As the distance between the fronts shrank, their thermal fields interacted, generating a maximum of $33.9^{\circ} \mathrm{C}$ when they met at $90.6 \mathrm{~s}$, very near the center.

On unloading, the temperature at the centerline initially dropped to $20^{\circ} \mathrm{C}$, as a result of a small amount of "precooling" during premature (diffuse) $A$ formation. There was (again) a nucleation of $A$ at the same point the loading fronts coalesced, along with a corresponding stress rise as the nucleation barrier was overcome. The pair of $M^{+} \rightarrow A$

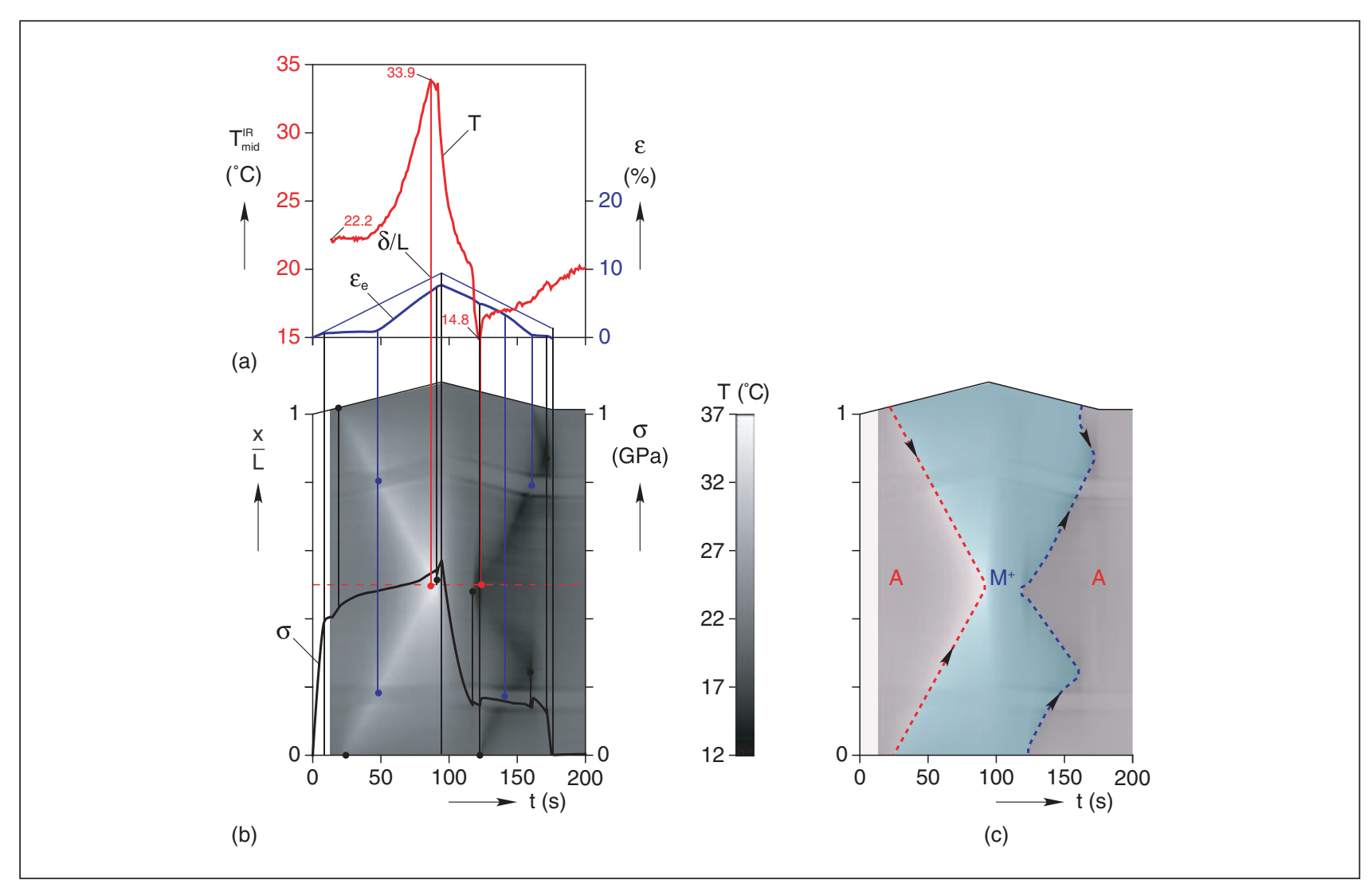

Fig. I I: Tensile experiment on SE wire in room temperature air at $\delta / L= \pm I \times I 0^{-3} \mathrm{~s}^{-1}$ : (a) histories of global strain $(\delta / L)$, local strain $\left(\varepsilon_{\mathrm{e}}\right)$, and the IR temperature at the initial wire mid-span ( $\left.T_{\text {mid }}^{I R}\right)$; (b) IR grayscale contour map in space $(x / L)$ and time $(t)$ with stress history overlaid; and (c) derived phase map 
fronts diverged at a nearly constant rate, but since they were so close, they quickly cooled the specimen to $15^{\circ} \mathrm{C}$ and the stress dropped accordingly. At this point, the stress was low enough to overcome the nucleation barrier at a warmer section of the specimen, and the favored location was near the lower grip. The nucleation at $122.6 \mathrm{~s}$ caused another stress rise. Now that the specimen had three fronts, each front propagated slower than before cooling the specimen less, so the front temperatures rose to about $18^{\circ} \mathrm{C}$. This temperature of all three fronts dropped again as the two lower fronts got closer to each other, and the stress decreased to a minimum of $143 \mathrm{MPa}$ when the lower two fronts coalesced at $159.1 \mathrm{~s}$. This stress was lower enough to nucleate a front at the upper grip. Because there were then two fronts instead of three, the remaining fronts increased in speed (and cooling rate) so the stress continued to decrease until transformation completed at $171 \mathrm{~s}$. The experiment exhibited a "serrated" stress history during unloading as self-cooling from transformation caused the stress to drop, but the low stress allowed new nucleations of $A$ in cooler areas of the specimen, resulting in less self-cooling until fronts coalesced, and then were required to speed up again.

When the specimen was pulled 10 times faster yet in the experiment shown in Fig. 12, multiple nucleations occurred during loading within the gage length due to temperature fluctuations that allowed mechanical nucleation barriers to be overcome even at locations without any obvious "imperfections." As with the two previous experiments, the first two $A \rightarrow M^{+}$fronts emerged from the two grips just after the knee in the stress history. The temperature (and stress) continued to rise as the fronts distanced themselves from the grips, quickly reaching $35^{\circ} \mathrm{C}$. It is important to remember that the nucleation stress $\sigma_{N}$ is temperature dependent, so cooler material will have a lower $\sigma_{\mathrm{P}}$. This means that while the two fronts propagated at $35^{\circ} \mathrm{C}$ and $530 \mathrm{MPa}$, there was a cooler location where $530 \mathrm{MPa}$ was just above its nucleation stress. Using this logic, whenever the temperature difference between a section of untransformed wire and a propagating front is above a critical value $\Delta T_{\mathrm{N}}=13^{\circ} \mathrm{C}$ (see the arrows in Fig. 6b), a nucleation will occur that results in a brief stress drop (in fact these can be heard as an audible click from the wire).

This heat/nucleate process repeated itself four times during loading. Each time, a new nucleation momentarily lowered the stress, but self-heating caused it to rise again. By $5.8 \mathrm{~s}$, there were 10 propagating fronts, making heating of the specimen more uniform. With no "cold spots" remaining to generate enough temperature difference to overcome $\Delta T_{\mathrm{N}}$, there could be no new $M^{+}$nucleations. Without additional nucleations, the material continued to self-heat, rising to a

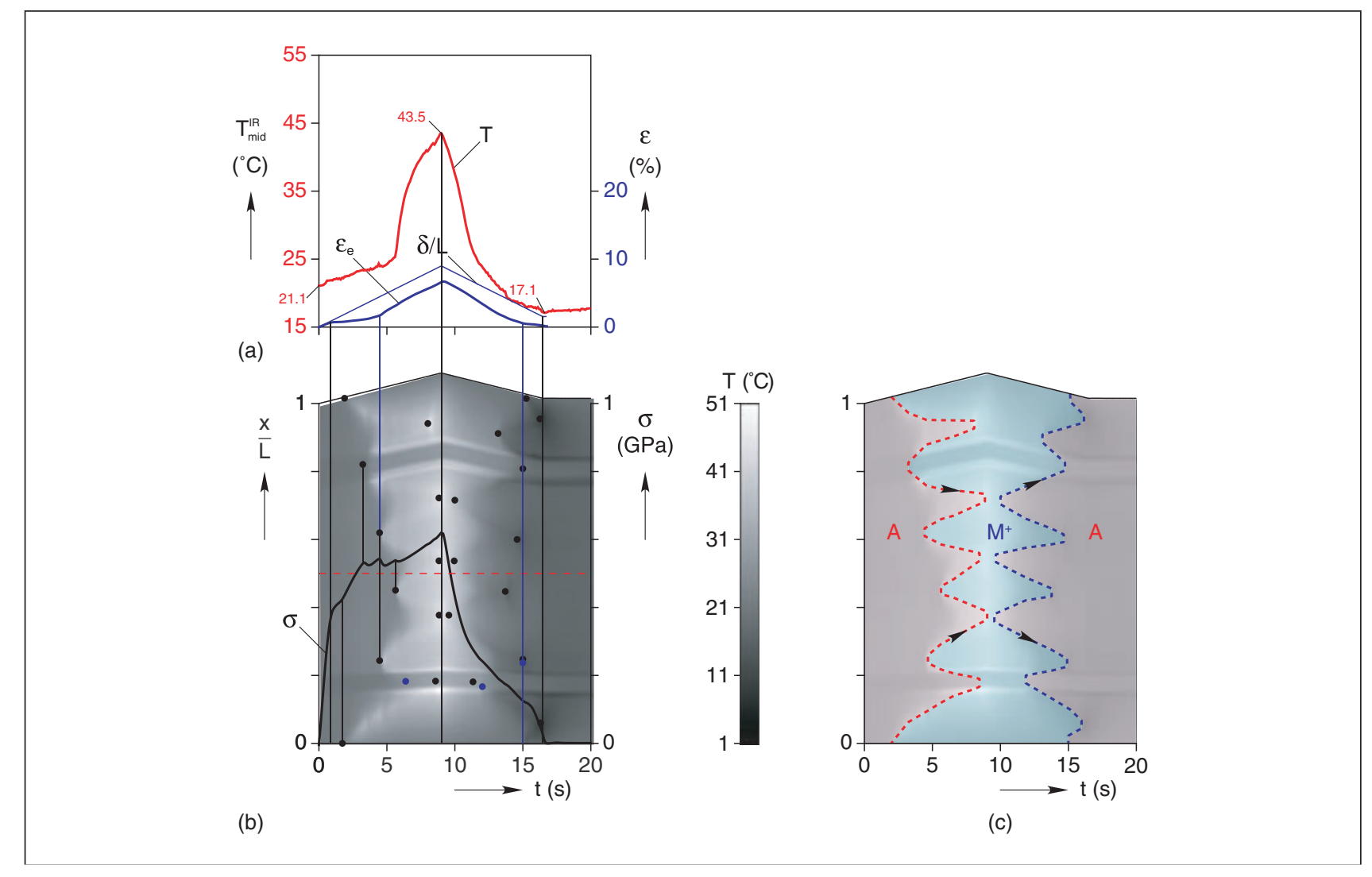

Fig. I2: Tensile experiment on SE wire in room temperature air at $\dot{\delta} / L= \pm I \times 10^{-2} \mathrm{~s}^{-1}$ : (a) histories of global strain $(\delta / L)$, local strain $\left(\varepsilon_{\mathrm{e}}\right)$, and the IR temperature at the initial wire mid-span ( $T_{\text {mid }}^{I R}$ ); (b) IR grayscale contour map in space $(x / L)$ and time $(t)$ with stress history overlaid; and (c) derived phase map 
maximum local temperature of $51^{\circ} \mathrm{C}$ by the time transformation was finished. During this time, the serrated stress behavior was replaced by a steady stress rise, following the temperature rise, to finish at $621 \mathrm{MPa}$.

The opposite effect occurred on unloading. More extreme selfcooling resulted in the nucleation of 12 different $M^{+} \rightarrow A$ fronts, each at a site where two $A \rightarrow M^{+}$fronts coalesced (imperfections now exist for the reverse transformation). The stress response shows a smoother path than it did during loading, because these imperfections reduced the effective nucleation barriers. When transformation finished at $15.7 \mathrm{~s}$, the material had cooled itself locally to $1^{\circ} \mathrm{C}$.

As was mentioned before, the final experiment at $\dot{\delta} / L=$ $\pm 1 \times 10^{-1} \mathrm{~s}^{-1}$ (see now Fig. 13) was performed near the limit of our load frame and data acquisition system, so stress, strain, and cross-head motion should only be considered qualitatively. The loading rate in this case is approximate, and unloading was terminated before the stress reached zero. Still, the IR data is reasonably accurate, taken at $60 \mathrm{~Hz}$, and it shows the previous trends taken to the extreme. After two fronts emerged from the grips, the first nucleations of $M^{+}$ occurred near $0.35 \mathrm{~s}$, immediately heating to over $50^{\circ} \mathrm{C}$. With a $30^{\circ} \mathrm{C}$ difference between front temperature and ambient, a new nucleation occurred a fraction of second later. By $0.6 \mathrm{~s}$, there were 12 obvious nucleations and perhaps two more behind the laser tags, resulting in as many as 30 fronts. The nucleations were spaced so tightly that heating of the wire was rather uniform until the fronts coalesced between 0.9 and $1 \mathrm{~s}$. Using our previous value of 2.7 wire diameters for each nucleation event, this represent $87 \%$ of the wire length consumed by nucleation events alone, leaving little room for fronts to propagate. In this way, transformation kinetics in the near adiabatic response of the wire is nucleation dominated, with only a little "growth phase." The same thing happened on unloading, as multiple $M^{+} \rightarrow A$ fronts nucleated until the temperature of the entire specimen dropped continuously, with a minimum of $17.1^{\circ} \mathrm{C}$ as fronts coalesced.

\section{SUMMARY AND CONCLUSIONS}

Shape memory alloys exhibit dramatic sensitivities in their superelastic responses at slow-to-moderate loading rates. First, a series of experiments on SM wire was presented at loading rates of $\dot{\delta} / L=4 \times 10^{-4} \mathrm{~s}^{-1}$ to $\dot{\delta} / L=4 \times 10^{-2} \mathrm{~s}^{-1}$ using both air and water as ambient media. The experiments demonstrated that rate sensitivity during stress-induced transformations in SMAs is in fact a temperature sensitivity, and that the heat transfer nature of the ambient media was just as influential as the loading rate in the

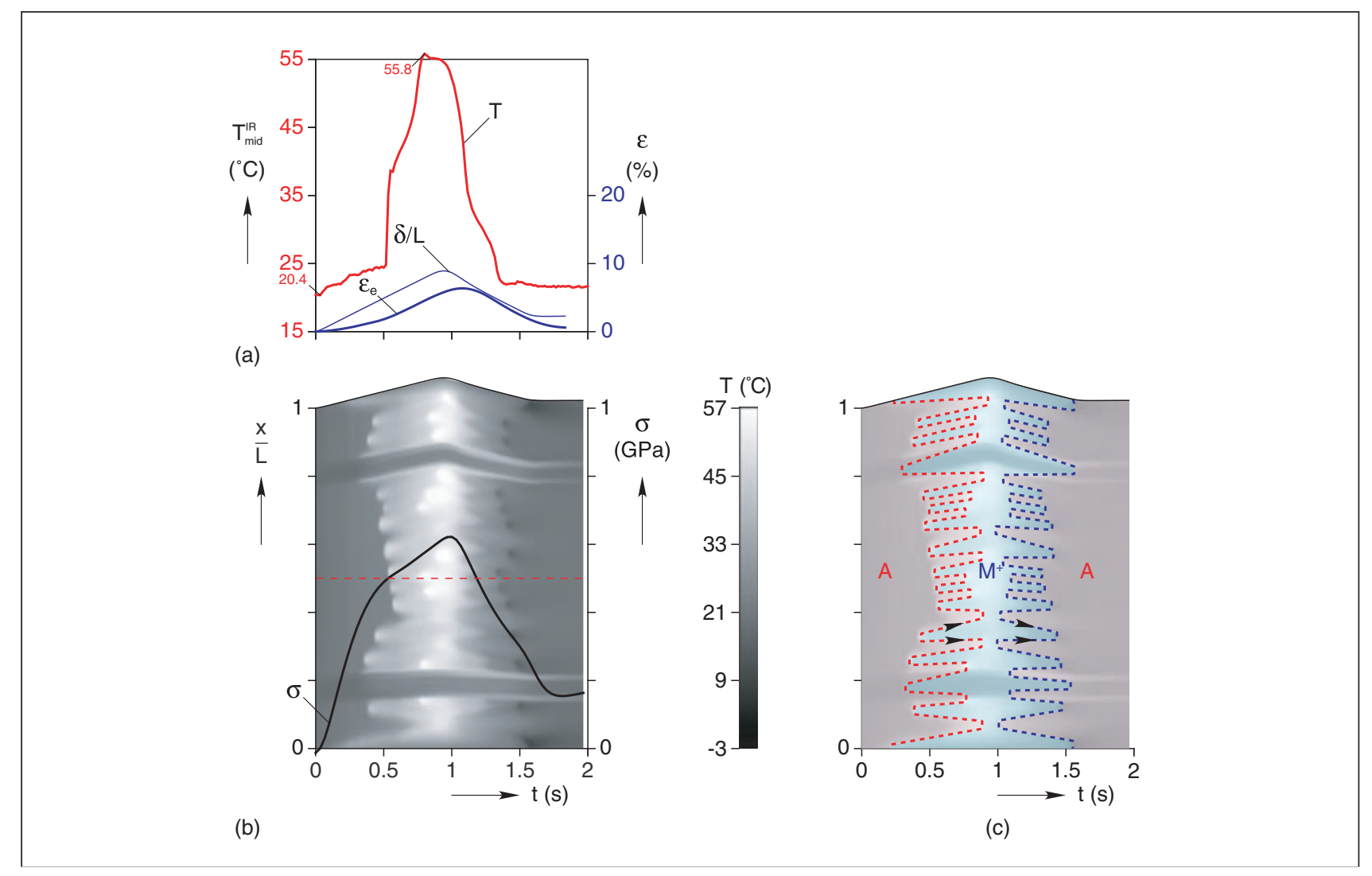

Fig. 13: Tensile experiment on SE wire in room temperature air at $\dot{\delta} \approx \pm I \times 10^{-1}$ : (a) histories of global strain $(\delta / L)$, local strain $\left(\varepsilon_{\mathrm{e}}\right)$, and the IR temperature at the initial wire mid-span $\left(T_{\text {mid }}^{I R}\right) ;(b)$ IR grayscale contour map in space $(x / L)$ and time $(t)$ with stress history overlaid; and (c) derived phase map 
mechanical response. This sensitivity comes from the strong thermo-mechanical coupling inherent to the material, arising from latent heat exchanges and temperature-dependent transformation stresses.

Details of rate sensitivity at the thermal time scale were explored with another series of five experiments, this time in air on the $\mathrm{SE}$ wire at rates ranging from $\dot{\delta} / L=1 \times 10^{-5} \mathrm{~s}^{-1}$ to $\dot{\delta} / L=1 \times 10^{-1} \mathrm{~s}^{-1}$, spanning the range from isothermal to near adiabatic responses. Local transformation fronts were tracked using full-field temperature histories from an IR video camera. These fronts, first introduced in Part 3, localize heat generation to near point sources (or sinks), amplifying coupling effects at even relatively low global strain rates. Front morphology was used to explain details of rate dependence, including the origin of constant, serrated, and smoothly varying stress responses. Overall, the isothermal response exhibited only one or two fronts, propagating at constant rate during the plateau stresses of $A \rightarrow M^{+}$ and $A \leftarrow M^{+}$transformations. Faster rates resulted in the nucleation of more fronts as mechanical nucleation barriers were surmounted via the nonuniform temperature fields in the specimen and the temperature dependence of the nucleation and propagation stresses. At near adiabatic rates (for air), the transformations were nucleation dominated, resulting in large changes in temperature and stress during transformation.

One can think of four different time scales involved in SMA behavior: (1) the smallest time scale is related to the time for an elastic wave to traverse a specimen, about $1 \times 10^{-5} \mathrm{~s}$ in a $30 \mathrm{~mm}$ specimen; (2) the next is the time that martensitic phase transformation can theoretically propagate through a specimen, which is perhaps $10 \times$ that of an elastic wave (see ref. ${ }^{14}$ ); (3) the third time scale is the time associated with typical loading rates used for material characterization, like the experiments shown here, between 1 and $10^{4} \mathrm{~s}$; (4) the last is the thermal time scale, which is dependent on the ambient media and geometry of the SMA. For the SM wire held vertically in air, we showed a characteristic time of about $6 \mathrm{~s}$ for heat transfer to air. The first two time scales are clearly many orders of magnitude smaller than the last two, so unless one is interested in extremely dynamic loading rate, they can be safely ignored. The last two, however, are close enough that one cannot ignore their coupling, unless the loading rate is extremely slow. Thus, the five decades in loading rate shown give a reasonably comprehensive picture of the variety of responses that may arise.

This article has explained the origin of rate thermal sensitivities in superelastic, or stress-induced martensitic transformations in SMAs. In other dead loading, temperature-induced transformation experiments, we have observed the same thermo-mechanical coupling, yet it is more difficult to precisely control the temperature rate as one can the displacement rate here. Even so, it is still critical that the experiment designer consider ambient media and thermal boundary conditions with as much care as one would a load cell and extensometer. Experimentalists wishing to produce good quality constitutive data should be cognizant of the tendency for thermo-mechanical coupling

\section{Table I -Properties of SM wire and SE wire}

\begin{tabular}{|c|c|c|c|c|}
\hline PROPERTY & SYMBOL & SM WIRE & SE WIRE & UNITS \\
\hline Wire diameter & $d$ & 1.067 & 0.762 & $\mathrm{~mm}$ \\
\hline Specimen free length & $L$ & 63.5 & 60 or 33.3 & $\mathrm{~mm}$ \\
\hline Elastic modulus $(A)$ & $E_{\mathrm{A}}$ & $78\left(100^{\circ} \mathrm{C}\right)$ & $70\left(20^{\circ} \mathrm{C}\right)$ & $\mathrm{GPa}$ \\
\hline Reference temperature & $T_{\mathrm{R}}$ & 31.4 & -10 & ${ }^{\circ} \mathrm{C}$ \\
\hline $\begin{array}{l}\text { Plateau stress slope } \\
\qquad\left(A \rightarrow M^{+}\right)\end{array}$ & $\mathrm{d} \sigma_{\mathrm{P}} / \mathrm{d} T$ & 7.8 & 6.7 & $\mathrm{MPa} /{ }^{\circ} \mathrm{C}$ \\
\hline Plateau strain $\left(A \rightarrow M^{+}\right)$ & $\Delta \varepsilon_{\mathrm{P}}^{A M^{+}}$ & $5.35\left(70^{\circ} \mathrm{C}\right)$ & $6.24\left(20^{\circ} \mathrm{C}\right)$ & $\%$ \\
\hline $\begin{array}{l}\text { Stress hysteresis } \\
\qquad\left(A \leftrightarrow M^{+}\right)\end{array}$ & $\Delta \sigma_{\mathrm{P}}$ & $\geq 250$ & $\geq 200$ & $\mathrm{MPa}$ \\
\hline Yield strength $(A)$ & $\sigma_{Y}$ & $\approx 600$ & $\approx 600$ & $\mathrm{MPa}$ \\
\hline \multicolumn{5}{|l|}{ DSC values: } \\
\hline$M \rightarrow A$ finish temperature & $A_{\mathrm{f}}$ & 56 & 13 & ${ }^{\circ} \mathrm{C}$ \\
\hline$M \rightarrow A$ start temperature & $A_{s}$ & 26 & -30 & ${ }^{\circ} \mathrm{C}$ \\
\hline$R \leftarrow A$ start temperature & $R_{\mathrm{s}}$ & 52 & 13 & ${ }^{\circ} \mathrm{C}$ \\
\hline$R \leftarrow A$ finish temperature & $R_{\mathrm{f}}$ & 31 & 30 & ${ }^{\circ} \mathrm{C}$ \\
\hline$M \leftarrow R$ start temperature & $M_{s}$ & -7 & -73 & ${ }^{\circ} \mathrm{C}$ \\
\hline$M \leftarrow R$ finish temperature & $M_{\mathrm{f}}$ & $<-50$ & -120 & ${ }^{\circ} \mathrm{C}$ \\
\hline $\begin{array}{l}\text { Specific latent heat } \\
\qquad(M \rightarrow A)\end{array}$ & $\Lambda^{M \rightarrow A}$ & 19.7 & 15 & $\mathrm{~J} / \mathrm{g}$ \\
\hline Specific heat & $c_{\circ}$ & 0.45 & 0.45 & $\mathrm{~J} /(\mathrm{gK})$ \\
\hline \multicolumn{5}{|l|}{ Supplier values (typical): } \\
\hline Mass density & $\rho$ & \multicolumn{2}{|c|}{$6.45-6.5$} & $10^{6} \mathrm{~g} / \mathrm{m}^{3}$ \\
\hline Melting temperature & $T_{\mathrm{m}}$ & \multicolumn{2}{|c|}{$1250-1300$} & ${ }^{\circ} \mathrm{C}$ \\
\hline $\begin{array}{l}\text { Coefficient of thermal } \\
\text { expansion }(A)\end{array}$ & $\alpha_{A}$ & \multicolumn{2}{|c|}{$10-11$} & $10^{-6} / \mathrm{K}$ \\
\hline $\begin{array}{l}\text { Coefficient of thermal } \\
\text { expansion }(M)\end{array}$ & $\alpha_{M}$ & \multicolumn{2}{|c|}{$6.6-8.0$} & $10^{-6} / \mathrm{K}$ \\
\hline Thermal conductivity $(A)$ & $K_{A}$ & \multicolumn{2}{|c|}{18} & $\mathrm{~W} /(\mathrm{m} \mathrm{K})$ \\
\hline Thermal conductivity $(M)$ & $K_{M}$ & \multicolumn{2}{|c|}{8.65} & $\mathrm{~W} /(\mathrm{m} \mathrm{K})$ \\
\hline Electrical resistivity $(A)$ & $\rho_{\mathrm{e}}^{A}$ & \multicolumn{2}{|c|}{$0.6-0.8$} & $10^{-6} \Omega \mathrm{m}$ \\
\hline Electrical resistivity $(M)$ & $\rho_{\mathrm{e}}^{M}$ & \multicolumn{2}{|c|}{$0.75-1.0$} & $10^{-6} \Omega \mathrm{m}$ \\
\hline Ultimate strength & $\sigma_{U}$ & \multicolumn{2}{|c|}{$\approx 1.5$} & $\mathrm{GPa}$ \\
\hline Ultimate failure elongation & $\varepsilon \cup$ & \multicolumn{2}{|c|}{$15-25$} & $\%$ \\
\hline Poisson ratio $(A)$ & $v_{\mathrm{A}}$ & \multicolumn{2}{|c|}{0.33} & - \\
\hline
\end{tabular}

to shift observed transformation stresses and temperatures away from their true isothermal values at rates one would consider quasi-static for traditional metals.

It should be mentioned again that the localized behavior of strain and temperature fields shown here is common to as-received (virgin) Nitinol wire when loaded in tension. Preconditioned (or trained) SMA wire (for example, Flexinol ${ }^{\circledR}$ from Dynalloy Corp. in Tustin, CA) does not exhibit the same superelastic behavior, having instead a nonlinear response with positive tangent modulus during stress-induced transformation with no distinct plateaus. One can imagine that cycling virgin Nitinol at moderate loading rates to shakedown the response to a repeatable limit cycle will likely create a proliferation of nucleation events that result in graded properties in the wire that no longer favors the propagation of transformation fronts. Thus, in preconditioned SMA wire 
thermo-mechanical coupling still exists, but since transformation now occurs in a relatively diffuse manner, the heat sources/sinks during transformation are more evenly distributed across the wire length. This likely results in lower temperature extremes due to self-heating/self-cooling. Thus, the regime for isothermal versus adiabatic mechanical behavior in precycled SMA wire will shift toward higher loading rates. The results shown here, however, do suggest that the rate at which precycling occurs and the prevailing thermal environment will influence the resulting limit cycle behavior and the wire's ultimate fatigue resistance (durability).

We conclude by giving the properties of two NiTi alloys being studied, summarized below in Table 1, which include values measured here and some other typical values as provided by the wire manufacturer. We hope this is useful to give one a sense of the variability and similarities among different NiTi alloys.

\section{ACKNOWLEDGMENTS}

We again appreciate the invitation from Nilesh Mankame (General Motors) to write this series of papers. We gratefully acknowledge the financial support for this work, provided by the National Science Foundation and General Motors Corp. through the GM/UM Collaborative Research Laboratory in Smart Materials and Structures.

\section{References}

1. Shaw, J.A., Churchill, C.B., and Iadicola, M.A., "Tips and Tricks for Characterizing Shape Memory Alloy Wire: Part 1 Differential Scanning Calorimetry and Basic Phenomena," Experimental Techniques 32(5):55-62 (2008).

2. Churchill, C.B., Shaw, J.A., and Iadicola, M.A., "Tips and Tricks for Characterizing Shape Memory Alloy Wire: Part $2-$ Fundamental Isothermal Responses," Experimental Techniques 33(1):51-62 (2009).
3. Churchill, C.B., Shaw, J.A., and Iadicola, M.A., "Tips and Tricks for Characterizing Shape Memory Alloy Wire: Part 3 - Localization and Propagation Phenomena," Experimental Techniques 33(5):70-78 (2009).

4. Shaw, J.A., Material Instabilities in a Nickel-Titanium Shape Memory Alloy, PhD Dissertation, The University of Texas at Austin, Department of Aerospace Engineering, Jan. 1997.

5. Shaw, J.A., and Kyriakides, S., "Thermomechanical Aspects of NiTi," Journal of the Mechanics and Physics of Solids 43(8): 1243-1281 (1995).

6. Otsuka, K., and Ren, X., "Physical Metallurgy of Ti-Ni-Based Shape Memory Alloys," Progress in Materials Science 50:511-678 (2005).

7. Patoor, E., Eberhardt, A., and Berveiller, M., "Micromechanical Modeling of the Superelastic Behavior," Journal de Physique IV 5(C2):501 (1995).

8. Gall, K., and Sehitoglu, H., "The Role of Texture in Tensioncompression Asymmetry in Polycrystalline NiTi," International Journal of Plasticity 15:69-92 (1999).

9. Shaw, J.A., and Churchill, C.B., "A Reduced-order Thermomechanical Model and Analytical Solution for Uniaxial Shape Memory Alloy Wire Actuators," Smart Materials and Structures 18(6):065001 (21pp) (2009).

10. Hope, P.S., and Ward, I.M., "The Hydrostatic Extrusion of Polymethylmethacrylate," Journal of Materials Science 15:2207-2220 (1980).

11. Bramley, A.N., and Mellor, P.B., "The Effect of Strain Rate on the Plastic Flow Characteristics of Steel and Aluminum Sheet," Journal of Strain Analysis 1(5):439-446 (1966).

12. Iadicola, M.A., and Shaw, J.A., "Rate and Thermal Sensitivities of Unstable Transformation Behavior in a Shape Memory Alloy," International Journal of Plasticity 20:577-605 (2004).

13. Iadicola, M.A., and Shaw, J.A., "An Experimental Method to Measure Initiation Events During Unstable Stress-Induced Martensitic Transformation in a Shape Memory Alloy Wire," Smart Materials and Structures 16:S155-S169 (2007).

14. Escobar, J.C., Clifton, R.J., and Yang, S.-Y.. "Stress-waveinduced Martensitic Phase Transformations in NiTi." Furnish, M.D., Chhabildas, L.C., and Hixson, R.S., (eds), Shock Compression of Condensed Matter, AIP Conference Proceedings \#505, American Institute of physics, pp. 267-270 (1999). 